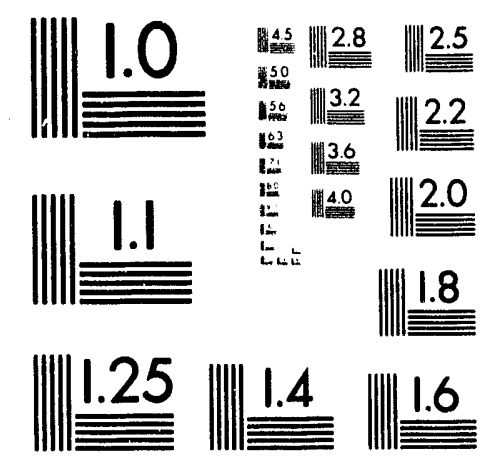



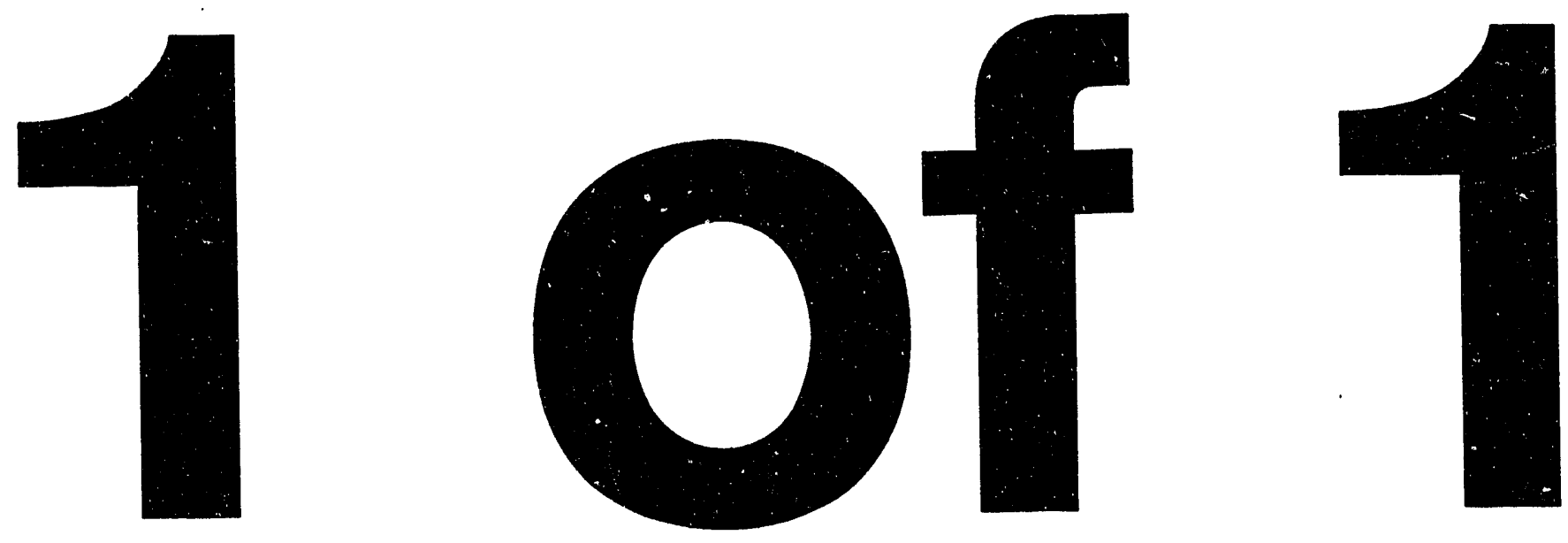
SARM

SAFETY ANALYSIS AND RISK MANAGEMENT
W S R C - R P- $92-426$

Key Words: Steam Explosion

Fuel Aluminum

Reactor Accidents

Retention: Lifetime

\section{A Review of Vapor Explosion Information Pertinent to the SRS Reactors}

\section{B y}

M. L. Hyder

D. K. Allison

\section{Safety Analysis Group}

Savannah River Laboratory

March 1992

Authorized Derivative Classifier
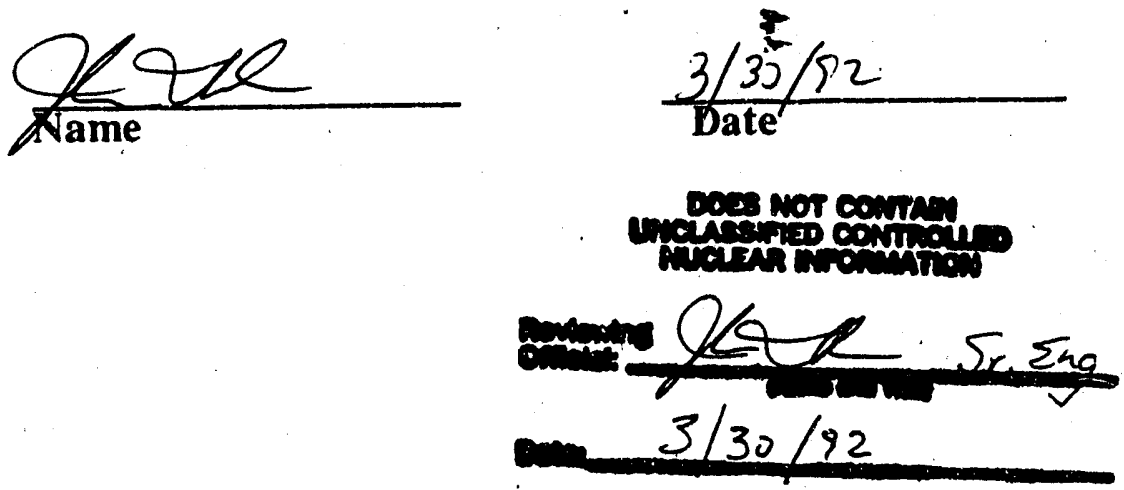

Westinghouse Savannah River Company Savannah River Site

Aiken, SC 29801

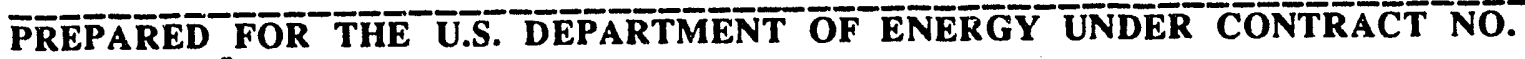
DE-AC09-8భSR 18035

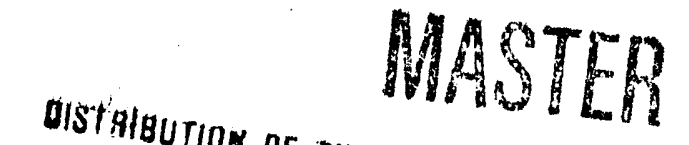




\section{DISCLAMMER}

This report was prepared as an account of work sponsored by an agency of the United States Government. Neither the United States Government nor any agency thereof, nor any of their employees, makes any warranty, express or implied, or assumes any legal liability or responsibility for the accuracy, completeness, or usefulness of any information, apparatus, product, or process disclosed, or represents that its use would not infringe privately owned rights. Reference herein to any specific commercial product, process, or service by trade name, trademark, manufacturer, or otherwise does not necessarily constitute or imply endorsement, recommendation, or favoring by the United States Government or any agency thereof. The views and opinions of authors expressed herein do not necessarily state or reflect those of the United States Government or any agency thereof. 
Document: WSRC-RP-92-426

Title: A Review of Vapor Explosion Information Pertinent to the SRS Reactors

APPROVALS

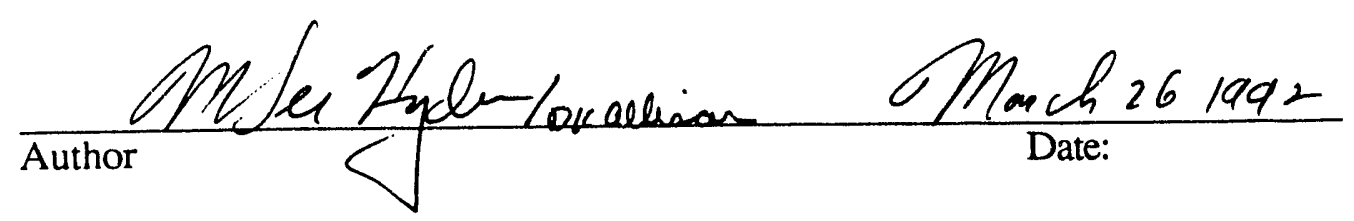

BIt. Visdenfects $\quad 4 / 22192$

Technical Reviewer Date:
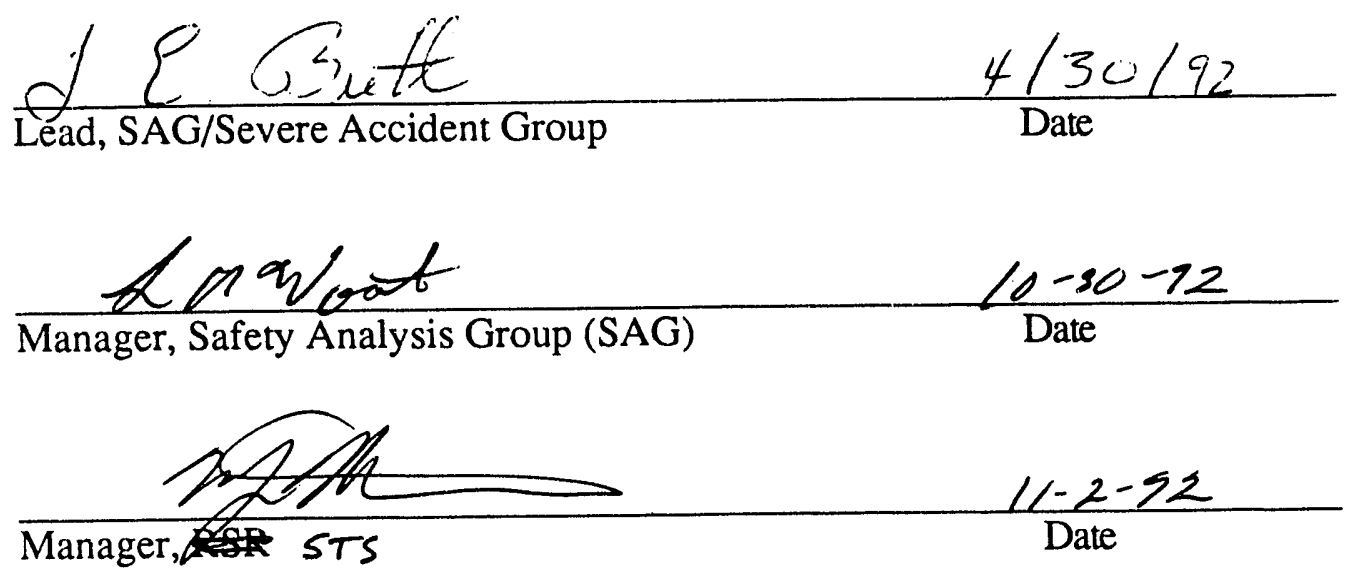


\title{
A Review of Vapor Explosion Information Pertinent to the SRS Reactors
}

\author{
M. L. Hyder \\ D. K. Allison
}

April, 1992

\section{Introduction}

Vapor explosions are explosive events resulting from the mixing of two liquids, one of which is heated to a temperature well above the boiling point of the second. Under some circumstances mixing of the liquids can boil part of the lower boiling liquid so quickly that the expanding vapor generates a strong pressure wave and explosion. If the lower boiling liquid is water, as is frequently the case, the event is called a "steam explosion".

Many vapor explosions have occurred as the result of accidents in industrial processes, including the nuclear industry. Steam explosions have occurred following the contact between water and a great variety of hot liquids, including molten metals (iron, aluminum, tin, etc.), molten salts, liquid phosphorous, etc. The results have sometimes been severe enough to damage massive equipment and cause serious or fatal injuries. (BN1) Molten nuclear reactor fuel has caused damaging steam explosions.

Analyses in support of the K-Reactor Probabilistic Risk Assessment have shown that steam explosions generated by the interaction of molten reactor fuel with water contribute significantly to the risk of reactor operation at the SRS. (WB1) This calculated risk incorporates a conservative treatment of the uncertainties associated with such explosions.

Study of steam explosions involving molten reactor materials has been included in the Severe Accident Analysis Program (SAAP) (MH1) in order to obtain a better evaluation of their importance, and, if possible, to find ways to avoid them. This paper presents a brief review and summary of steam explosion experience from literature accounts, along with the results of experimental studies from the SAAP. It concludes with an evaluation of current knowledge, and suggestions for future development.

II. Conceptual Models of a Steam Explosion.

\section{A. Mixed Systems}

A model of steam explosions that is widely accepted for a large class of explosions is shown by the sequence of conceptual drawings in Figure 1. Figure 1a shows a hot dense liquid falling freely through a lighter, volatile liquid. The temperature of the hot liquid exceeds the temperature of 
transition to film boiling, so that a vapor film separates the two fluids. In Figure 1b viscous effects cause the hot liquid to separate into smaller portions; this is the so-called premixing phase. Figure 1c indicates the sudden introduction of a triggering pressure pulse, here assumed to occur when the hot melt contacts the bottom of the vessel containing the fluids. In Figure 1d this pulse has caused rapid, intimate mixing of the two fluids; the vapor film has been broken down, and a quantity of superheated vapor has been generated. The expansion of this vapor generates a shock wave that continues the mixing and vapor generation process as it advances, so that it continuously builds its intensity. The result is an explosion driven by the heat energy of the hot fluid (Figure 1e). This model has been described in more detail by Fletcher and Anderson. (FA1)

This model has been assembled from a variety of sources, including smallscale laboratory studies, debris examination, energetic measurements, calculations, etc. As Taleyarkhan points out, it is now well accepted in the literature, although many details are open to debate. (RT1) This is because some of its bases are not very quantitative, and some details have not been well characterized by experiment. In particular, the amount of premixing occurring prior to the explosion is difficult to estimate, and may be very poor; (FA1) triggering processes in many experiments have been poorly characterized; and the expansion phase is extremely difficult to study in any detail. Nonetheless, the model appears to fit the available experimental data on vapor explosions. It leads directly to some qualitative conclusions regarding steam explosions, including the following:

1. For heat to be transferred from the hot liquid to the cold during the brief period of the explosion, the two fluids must be mixed on an intimate scale. Heat transfer calculations for metal melts and water show that this mixing must be on the scale of millimeters or below. Physical processes operating during the premixing phase generally do not cause mixing on a scale less than centimeters. Thus a triggering process causing intimate initial mixing is required to initiate the explosion.

2. Because of the intimate mixing occurring during the explosion, the hot phase is dispersed into relatively small particles. These will be cooled by the rapid heat transfer that drives the explosion, and will be recovered as fine solids.

3. Scale effects will be complex and geometry dependent. Each of the three parts of the explosion, premixing, triggering, and expansion, depends on scale and geometry, but this dependence is at best qualitatively known.

\section{B. Stratified Systems}

A second conceptual steam explosion process is shown in Figure 2. This is the situation which may occur if the hot dense phase reaches the bottom of the vessel and spreads out without freezing. The vessel now contains two stratified liquid layers, separated by a vapor film. Under these 
circumstances a trigger wave at the interface can produce a mixing wave that progresses over the surface, causing a kind of planar explosion. ( $\mathrm{AA1}, \mathrm{AA2}, \mathrm{AB1}$ ) The energetics will be limited by the mixing depth, and can vary considerably with the magnitude of the disturbance causing the initial explosion. (AA1) If the first explosion is not too disruptive, and the hot system is not frozen by it, further explosions can occur. Such behavior has been experimentally observed. (GG1)

The conclusions in the previous section concerning mixing scale, explosion scale, etc., apply to this mode of explosion for the mixed region of the two phases. This type of explosion is of greatest concern in the reactor case when considering the consequences of flooding a molten system with water.

The practical difference between pour-type and stratified mode explosions may not be too important; either is capable of generating a large, damaging explosion under circumstances that favor such an explosion.

\section{Experimental Bases.}

Corradini has recently reviewed the experimental literature on steam explosions, (MC1) but his review does not cover the field of aluminum-water reactions in detail. That is the purpose of this section.

\section{A. Aluminum-Water Experiments.}

No experiments have been done involving melts in which the chemical composition resembles actual fuel, with uranium and fission product contents. The best available approximation is melts of aluminum or its commercial alloys. It is reasonable to use pure aluminum as a stand-in for fuel, because aluminum represents well over 90 mole $\%$ of the fuel, and is largely responsible for its heat transfer and metallurgical properties. In addition, the oxide layer for $\mathrm{U}-\mathrm{Al}$ alloy is very similar to that present on pure aluminum so far as its reactivity and permeability are concerned. (RR1) However, steam explosions are known to be sensitive to details of composition, (NF1) and the presence of solid uranium aluminides in molten fuel near the melting point makes the situation more complex. These may affect the way in which the melt fragments in an explosion, or the chemical reactivity of the small fragments. The data base of experiments with molten aluminum and water is extensive, as will be shown; there have also been a number of experiments involving lithiumaluminum alloys and water, which are pertinent to the interactions of molten target and control rod material with water. (PC1,DA1,CG1,DA2)

- Extensive work has been performed within the aluminum industry on explosive interactions between molten aluminum and water. Much of this work was directed toward establishing the processes that trigger the steam explosions. Typical experiments involved dropping 50 pounds of melt into a limited amount of water, simulating conditions that might occur during an 
accident in the direct chill casting process. The early work by Long at ALCOA was the most comprehensive and established some primary conditions favorable for steam explosion initiation. (GL1) These conditions included: high melt temperature, low water temperature, large stream size, (high rate of entry of material into the water), small volume of water, and rusted or clean (non-oily) unpainted sizrfaces. Subsequent work at ALCOA concentrated on the evaluation of the effectiveness of different coatings in preventing steam explosions (HB1,HM1) A number of these experiments were triggered by the impact of a weight against the outside of the container.

Following the lead of those mentioned above, Lemmon of Battelle Columbus Laboratory performed a series of ex-periments with $10 \mathrm{lb}$ to $40 \mathrm{lb}$ of molten aluminum (AL1) Some of his tests involved no triggering of the explosion; others were triggered by various arrangement of exploding charges. $\mathrm{He}$ found that the use of high temperature melts (up to about $380^{\circ} \mathrm{C}$ superheat) enhanced the probability of triggering but did not guarantee it. He also found, by means of high speed photography, that aluminum-water reactions were initiated in times of the order of 1 millisecond.

Alexander et al. reported in 1982 the results of experiments involving triggered interactions between various metals and water. (AC1) A large portion of their work used aluminum. They were able to obtain semiquantitative information on the energetics of the reaction with the aid of crushblocks. The experiments employed typically $2.5 \mathrm{~kg}$ of molten material poured from a crucible into steel containers coated with RSG inhibiting paint. Triggering was accomplished with explosive cord. The energy released in a reaction was found to be proportional to the mass of melt, to vary exponentially with the superheat of the melt, to increase greatly when the water temperature was increased, and to be proportional to the depth of water. Because of possible inaccuracies in the crushblock technique, these trends must still be considered estimates.

The configuration of Alexander et al. was used by Page et al. to study steam explosions with lithium-aluminum alloys. (PC1) They succeeded in showing that the yield from an interaction involving $\mathrm{Al}-\mathrm{Li}$ varied exponentially with the $\mathrm{Li}$ content and that the length of explosive cord required to trigger the interaction decreased with superheat. Several pours were done without an external trigger, and no steam explosions occurred in any of these.

The work in the aluminum industry has included some unpublished work with lithium-aluminum alloys, which exploded readily and powerfully in experiments with $>25 \mathrm{lb}$ of melt. These experiments were qualitative and relatively few in number. (TW1, JJ1)

The industry conducted many hundreds of these experiments, and obtained dozens of explosions. In general, however, little was done to study quantitatively the triggering or energetics of steam explosions. Results 
show an apparent randomness in initiating of explosions, even when the conditions appear identical from one test to the next. However, trends regarding the mode of addition of the melt and the surface properties of the water vessel were identified. A few large explosions showed evidence of chemical reactions in the form of light emission. This was spectroscopically identified with AlO. (AL1)

- The aluminum industry association has also collected reports of actual plant accidents that appeared to involve steam explosions. Some have been highly energetic and damaging. These cases show that large, very energetic steam explosions can occur. Numerous accidents have also occurred in which water was injected into aluminum melts, causing part of the melt to be explosively ejected. (AA2)

- Experiments on the scale of a few kilograms have been performed by investigators in the nuclear industry. This includes a couple of experiments performed at the UKAEA Winfrith Laboratory, (FR1), six experiments recently performed by Rightley and Beck at Sandia National Laboratory. (RB1), and the experiments of Higgins. (HH1)

Rightley and Beck performed six tests with 2 to $10.3 \mathrm{~kg}$ of $\mathrm{Al}$ with melt superheats ranging from $67^{\circ} \mathrm{C}$ to $611^{\circ} \mathrm{C}$. Four steam explosions were observed. These occurred at the high end of the temperature range, and three were judged to have involved substantial chemical energy. Two of these were artifically triggered. The two tests at $67^{\circ}-77^{\circ}$ superheat (one triggered, one untriggered) did not involve steam explosions. In their report, Rightley and Beck propose a superheat threshold of about $167^{\circ} \mathrm{C}$ below which chemical involvement will not occur.

Higgins reported in 1955 the results of pouring a one inch stream of 5 weight percent lithium-aluminum melt into a twelve inch diameter steel pipe containing 9.5 inches of water. Steam explosions were not initiated in nine untriggered tests. Four tests triggered with a blasting cap produced violent reactions. Six triggered tests with molten aluminum did not result in steam explosions.

- Small scale experiments, on the order of ten grams, have been performed by L. S. Nelson at Sandia National Laboratory. These involved melt falling into water and, in most cases, triggering by explosive shocks. These experiments have substantiated the potential importance of surfaces in explosion triggering, (NE1) and have also shown that the energy required for triggering can vary considerably with alloy composition. In one case a massive chemical explosion was induced by triggering a droplet of aluminum that had entered the water at a temperature of about $1500^{\circ} \mathrm{C}$; this was the only experiment in which chemical reaction was observed. (ND2) The data obtained by Nelson on triggering pressures, explosive yields, and debris sizes, are the best available, and are used below in comparisons between experiment and theory. (ND2, NF2) 
- Briggs conducted experiments in which 10 to $20 \mathrm{~kg}$ of aluminum was poured into a small vessel containing 15 to $20 \mathrm{~cm}$ of water. (AB1) The melt temperature was about $800^{\circ} \mathrm{C}$. Explosions ranging from moderate to strong were observed in several experiments. These experiments were of interest in that (1) the initiation of the explosions was observed by high speed photography; (2) The explosions generally did not occur until the aluminum was partly in a stratified configuration, and seemed to be triggered by interactions of small disturbances with the edge of the vessel; and (3) Bright light was seen in the two largest explosions, but only after the melt and spray had been thrown into the air by the explosion. The experimenters attribute this to ignition in air rather than interaction with water.

- Tests of melting of U-Al fuels were conducted in the SPERT reactor, using plate fuel as well as short sections of SRS fuel. Melting was initiated by a fast, intense iuclear transient sufficient to melt part of the fuel. The behavior of the molten and residual material was then determined from post-test examinations. With one exception, described below, no explosions occurred. (ES1)

- Morin melted unirradiated fuel in the presence of rapidly flowing steam, and allowed the resulting melt to flow or be carried into water. No explosions occurred. (MH2)

- Greene has poured aluminum into trays of water to measure spreading and cooling effects. His work was done with $\mathrm{kg}$ or $10-\mathrm{kg}$ batches of aluminum, always poured through an orifice. The melt superheat was less than $100^{\circ} \mathrm{C}$. In about 70 tests no explosions occurred. In an extension of this work the breakup of a coherent pour stream of aluminum in a deep water tank was observed and characterized. Again, no explosion was observed. (GG2) Similar experiments have recently been conducted at Argonne National Laboratory. (DC1)

- An unusual and interesting experiment was conducted by the UKAEA to attempt to model the SL-1 accident described in the following section. (WR1) A 1/30 scale model of the reactor vessel was built, and aluminum foil inside the vessel was suddenly melted in place by an electric discharge while submerged in the water. An explosion was obtained which had very similar properties to those of the SL-1 accident. Unfortunately, the condition of the debris from this test was not reported.

- A variety of experiments with lithium-aluminum alloy, ranging up to 1 $\mathrm{kg}$ in melt mass, were done in support of the K-Reactor restart. The molten alloy, typically about $3 \%$ lithium by weight, was poured into water in the bottom of an instrumented SRS septifoil housing. No steam explosions occurred, although in some cases shocks were introduced by mechanisms designed to resemble possible shock sources in the reactor. Pressure pulses associated with boiling were measured; these were typically of the order of 1 
atm or less. (DA2,CG1) These results were used as a basis for postulating a low probability of reactor damage as the result of control rod melting. (AH1)

\section{B. Nuclear Reactor Experience}

There have been a considerable number of cases in which reactor fuel was partially melted while in contact with coolant, but only a few of these have resulted in explosive phenomena. The extent to which the Chernobyl accident can be considered a steam explosion remains controversial, although the conditions prevailing in the reactor were favorable for such an explosion: the fuel was melted in place by a reactivity transient, and there was cold water present to interact with it. (AH2,IS1,FR2) (Although Taleyarkhan (RT1) has suggested that melting in place ensures dispersion of the melt in the water, the results of the other SPERT experiments and the recent review by Ellison (EH1) show that the melt tends to form a coherent mass. In the case of Chernobyl, which involved a fast power transient, there were an ample supply of triggers in any case.) In the cases of the BORAX, SPERT-1, and SL-1 incidents, it is much clearer that steam explosions occurred and damaged the reactor core.

In each of these cases a small reactor fueled with enriched uraniumaluminum alloy fuel underwent a reactivity transient severe enough to melt some of the fuel. BORAX and SPERT-1 were controlled experiments, and the latter was well instrumented. SL-1 appears to have been deliberately mis-operated, and the debris was carefully studied in a search for evidence of what happened. In each case an explosion occurred that disrupted the core and ejected material, but the reactor vessel survived.

In the case of SPERT-1 the evidence for a steam explosion was very good. Sensors showed that the reactivity transient had concluded a significant time before the explosion. (MS1) No triggering event was sensed prior to the explosion itself. Only a few per cent of the melted fuel was found to be oxidized. (ES1) A very limited amount of chemical reaction was also observed in the SL-1 accident, even though some of that fuel was heated enough to vaporize it. (SM1) The vapor would be expected to burn in water or steam, but any oxidation reaction evidently did not propagate to the remainder of the disrupted core. (BS1)

Ellison has studied the behavior of fuel that was locally overheated in SRS reactors. (EH1) Blistering and cracking of cladding occurred, and with further heating core material melted and was extruded through cladding cracks. Swelling and foaming of this material was caused by volatile fission products, and this helped extrude the core material out of the cladding. Melt masses were small, and no explosions occurred in these events.

C. Melt-Water Mixing (Premixing) 
For melt falling through water, the amount of mixing will vary with the velocity of entry, the stream diameter, and the depth. Greene's various experiments have defined a number of cases. (GG1,GG2) Small amounts of melt will tend to break up and freeze quickly. Larger pours in relatively shallow water will go to the bottom and spread. The idealized dispersed mass envisioned in many theories, as in Figure 1, will be encountered only for moderate amounts of melt entering a deep vessel, and even in this case it can only be a very approximate model. The premixing model has been addressed in more detail by wee and Frost, without however definitive conclusions. (LF1)

How closely would any of these models be approached in a severe accident in a SRS reactor? Inside the reactor, molten fuel would be expected to run down inside the housing, or down the outside once the housing is penetrated. If not quenched, it would then spread over the bottom of the vessel. Melt penetrating the primary cooling system would probably fall in a stream to the -40 foot floor and spread out over this. In no case would the mixing with water be very good. In-reactor melting experiments have shown that even for a transient overpower melt the molten fuel tends to move coherently. Good premixing would probably not occur in any case; but explosions involving a portion of the molten material could occur.

\section{Triggering Processes}

Triggering of steam explosions has been attributed to a variety of factors, including entrapment of water beneath a mass of melt, chemical reactions, surface roughness, etc. Experiments have made it clear that triggering can occur when the vapor film about the melt particles is condensed or compressed so that the two fluids come into direct contact. Nelson's experiments have shown that this requires a pressure pulse of approximately 20 atmospheres ( $2 \mathrm{MPa}$ ). (NF1) Once contact is established, the resultant heat transfer and sudden steam generation p:oduce an explosion involving the outer part of a $1 \mathrm{~cm}$ melt drop. In an ensemble of droplets the same shock could produce this effect over the whole ensemble in a time that is short compared to the time required for heat transfer and steam generation; the result would be an explosion that would involve a large volume of material and could serve as an initiating shock over a still larger volume.

Note that the initial explosion involves only the outer part of a $1 \mathrm{~cm}$ drop. In Nelson's single drop experiments he observed (using a high speed camera) a sequence of pulsing explosions over a period of time (about $0.01 \mathrm{sec}$ ) as melt not involved in the initial explosion interacts with water. (NF1) The explosions were several milliseconds apart. The bulk of the drop continued to fall, as evidenced by the center of the successive explosions. In some cases the second explosion was much larger than the first. The original steam bubble pulsed but did not collapse before the second explosion occurred. The impression is that the droplet interacted by layers until it 
was complete; and the result of the first explosion was conditions favorable for triggering subsequent explosions.

An interesting consequence of this observation is that only a fraction of the heat of the droplet is involved in the initial explosion; the efficiency and magnitude of the initial explosion are therefore much less than the theoretical maximum. In a large explosion involving many drops only a portion of the available heat might be involved in the principal explosive process.

In Nelson's and other experiments triggering is accomplished through an explosive discharge that produces a strong pressure wave. What processes produce the spontaneous triggering that is seen in large untriggered experiments? Greene in his study of $\mathrm{Li}-\mathrm{Al}$ alloy $(100 \mathrm{~g})$ in water, attempted to trigger explosions with various mechanical shocks without success. (GG2) He observed natural pressure pulses in his system, resulting from the boiling and quenching process, of one atmosphere or more, but no explosions. Anderson et al. observed amplification of a pressure wave and explosion triggering in a partially stratified system at the point where the wave contacted the vessel wall. (AA1) Similar observations were made by Briggs. (AB1) It is well known that amplifications of shock waves can occur locally by reflection at walls, and particularly at corners. It is plausible that the very violent boiling that occurred in the aluminum industry experiments, in which the melt to water ratio is very high, can produce pressure pulses of several atmospheres, and that these can be amplified locally through reflections. In Greene's large scale aluminum-water experiments, in which no explosion occurred, there was a large excess of water and there were no walls near the pour point; the melt-water interface never reached a wall. (GG1) The aluminum industry experiments were performed with a rectangular basin of water. It would be interesting to repeat these experiments in a round-bottomed container, in which there are no corner reflections.

Berman and Beck have noted that pressure alone may not be a sufficient measure of trigger strength, and have suggested that pressure $\mathrm{x}$ impulse is a better cne. (BB1) They also noted that stronger triggers may in some cases cause stronger explosions. Nelson's data support the premise that trigger pressure alone does not determine the effectiveness of a trigger in setting off a steam explosion.

Another possibility sometimes suggested is that steam explosions are triggered when water is trapped by the melt. Numerous observation 7 show that water entrapment does not necessarily have this result. For Ex nple, quenched debris from pours of aluminum into water typically contains many voids from entrapment of water, even though no explosion occurred. Slabs of aluminum from Greene's experiments show depressions on the bottom from the entrapment and vaporization of water, but there were no explosions. Anderson and Armstrong injected water into aluminum melts without obtaining explosions. (AA2) Water entrapment is evidently not 
enough of an initiator to cause an explosion unless some second process breaks down the steam layer.

An interesting set of experiments was performed by Nelson et al., who induced steam explosions in droplets that had been allowed to fall onto various horizontal surfaces. (NE1) The explosive trigger used was marginal for producing explosions under these circumstances; the overpressure at the melt droplet was about $2 \mathrm{MPa}$. The geometry of this experiment is shown in Figure 3. The experimenters found that explosivity increased qualitatively with the wettability of the surface, with no explosions occurring on a water-repellent Grafoil surface, and vigorous explosions occurring on oxidized steel or copper. They postulated that a layer of trapped water underneath the drop was responsible for the explosion: the pressure wave forces the droplet to contact this water.

This explanation seems unlikely in that it requires an appreciable amount of water to remain in place for some period of time before the shock wave reaches the drop. An alternative is suggested by the scheme shown in Figures 4 and 5. The point of highest local pressure as the shock wave approaches the droplet will be at the interface with the horizontal surface where the shock is reflected. The molten aluminum will not wet most surfaces, so the nature of the interface will be as shown in the two cases. In the case of the wetted surface, the shock moving through the water phase will be reflected in the water right up to and even underneath the aluminum droplet. This could produce a higher local pressure and cause direct melt-water contact at this interface.

An interesting speculation, for which there is only circumstantial evidence, is that chemical reaction may be a trigger for steam explosions. In the following section it is pointed out that certain aluminum alloys can ignite spontaneously in water at high melt temperatures. However, the aluminum-water reaction adds to the gas layer between melt and water, so unless it produces a sudden strong pressure pulse it would not be a good trigger. One possible way in which chemical reaction might act as a trigger is by producing hydrogen. If air has been entrapped in the melt during its fall, there is the possibility of a local hydrogen ignition that might initiate an explosion. This is a speculative idea, as there is no direct evidence for such an occurrence.

Another reaction must be considered: oxidized iron surfaces are known to be favorable for triggering spontaneous aluminum-water explosions, (GL1) and iron oxides react exothermically with aluminum. (WL1, BS1) In most cases in which such explosions occurred, there is no evidence that there was substantial chemical reaction during the explosion, so that any chemical reaction was quite localized. Also, rough surfaces that do not react chemically with aluminum were found to be favorable for initiating explosions. (GL1) Thus while chemical reactions can't be ruled out as triggers, they are not the prime suspects in most cases. 
The conclusion of the above is that generally a steam explosion trigger will be a pressure wave, amplified perhaps by reflection from a surface. It follows that to decrease the likelihood of triggering, reflections should be minimized, as should the wetting of the surface. The Tarset $\otimes$ paints used in the aluminum industry address the latter aspect.

\section{E. Chemical Reaction}

Aluminum reacts with water as follows:

$$
2 \mathrm{Al}+3 \mathrm{H}_{2} \mathrm{O} \Rightarrow \mathrm{Al}_{2} \mathrm{O}_{3}+3 \mathrm{H}_{2}
$$

In most cases this chemical reaction between aluminum and water is insignificant, even in substantial steam explosions in which large areas of fresh aluminum surface are generated. This results from the rapid cooling of small aluminum particles in contact with water, and the rapid formation of a protective oxide layer on the surface of the aluminum droplet. Nonetheless, finely divided aluminum, if ignited, burns brightly in air or steam, and it is used as a pyrotechnic material in flares and similar devices, and also as an additive to high explosives. There is ample evidence that such burning can also occur in steam explosions, especially if the aluminum is at a temperature of $1000^{\circ} \mathrm{C}$ or more.

The aluminum oxide layer that inhibits chemical reaction is evidently very important in determining the chemical involvement in aluminum-water explosions. At high temperatures the oxide layer formed spontaneously in steam is about $200 \AA$ in thickness. Initially amorphous, the oxide layer crystallizes as it grows to its full thickness. (BG1) Epstein has proposed that steam explosions involving significant amounts of aluminum-water reaction can occur because the oxidation of aluminum is fast compared to the crystallization time of the oxide product, so that rapid chemical reaction can occur. (ME1) This oxide layer has considerable strength; unpublished melting studies performed by P. R. Monson at SRS have shown the oxide layer retaining its integrity about molten one-inch coupons of aluminum or uranium-aluminum fuel, even though the molten metal has sagged and deformed. An interesting observation is that at higher temperatures, above $1050^{\circ} \mathrm{C}, \mathrm{Al}_{2} \mathrm{O}_{3}$ in contact with $\mathrm{Al}$ metal is unstable with respect to the volatile species $\mathrm{Al}_{2} \mathrm{O}$ and $\mathrm{AlO}$; (RR1) it is at these temperatures that steam explosions with chemical reaction become much more probable. (RB1) Baker and Simms have speculated that the formation of the suboxides may be a reason for the delayed ignition of aluminum at $1600^{\circ} \mathrm{C}$. (BS1)

The available data on aluminum-water and aluminum-air reactions have recently been reviewed by Baker and Simms. (BS1) The ignition point for larger quantities of material is reported as about $1750^{\circ} \mathrm{C}$ for $\mathrm{cm}$-size particles, although delayed ignition occurred at temperatures down to $1600^{\circ} \mathrm{C}$. The burning process may involve burning of aluminum vapor. (LB1) 
Reaction of steam with a fresh aluminum surface in the temperature range of $800^{\circ}$ to $1200^{\circ} \mathrm{C}$ has been quantitatively measured. The reaction rate initially follows a curve as follows: (LB1)

$W^{3}=4 \times 10^{9} t e^{-(73500 / R T)}$

where $t$ is time in min, $T$ absolute temperature, $R$ the gas constant (1.987 $\mathrm{cal} / \mathrm{mole}{ }^{\circ} \mathrm{K}$ ), and $\mathrm{W}$ is the reaction rate in $\mathrm{mg} / \mathrm{cm}^{2}$. After $2.3 \mathrm{mg} / \mathrm{cm}^{2}$ has reacted, the reaction rate is fitted by the equation

$\mathrm{W}=2.5 \times 10^{8} \mathrm{te} \mathrm{e}^{-(73500 / \mathrm{RT})}$.

Experiments have been performed in which small pieces of aluminum were ignited under water through laser heating. Burning time for a 0.36 $\mathrm{mm} \mathrm{Al}$ particle in water was about $213 \mathrm{msec}$. (LM1) This particle size is on the upper end of particle sizes encountered in steam explosions, but this is a very long burning time. Material velocities in steam explosions typically reach hundreds of meters per second, so that the system is dispersed in a few milliseconds.

In actual steam explosions, chemical reaction of the $\mathrm{Al}$ with water, inferred from fast spectral measurements of $\mathrm{Al}$ emissions in an apparent hot flame, is ignited on a time scale of $10^{-4}$ seconds. The flame temperature is $3500^{\circ}$ to $3600^{\circ} \mathrm{K}$. The steam volume around the reacting area was observed to expand by tens of $\mathrm{cm}$ in $1 \mathrm{msec}$. (AL1)

The presence of alloying materials, as for example the $1 \%$ of magnesium present in 6061 alloy, can affect aluminum ignition. Nelson et al. observed transient ignition in small droplets of this alloy in water at $1000^{\circ} \mathrm{C}$. (NE1) Hyder observed ignition of a small pellet of uranium-aluminum alloy at about $1500^{\circ} \mathrm{C}$. (MH2) The emission of bright white light has been observed in steam explosion experiments at much lower temperatures; it was spectroscopically identified as an AlO emission spectrum, corresponding to chemical reaction and a very high temperature. (AL1) Rightley and Beck observed extremely violent steam explosions with light emission at temperatures above $1000^{\circ} \mathrm{C}$, and concluded that chemical energy was the dominant source of energy. Some of these experiments, including the only experiment that was not artificially triggered, were performed with the more reactive 6061 alloy, and it is possible that the chemical reaction could have triggered the explosion. (RB1)

Addition of lithium to aluminum has been found to increase the energetics of molten metal-water explosions; this increased energy is attributed to the chemical reaction of lithium and aluminum. (PC1) Nelson has found that significant lithium-water reaction can occur in the quenching of lithiumaluminum melts, even without the fine subdivision associated with a steam explosion. The amount of reaction was fairly reproducible as a function of temperature. At temperatures to $1000^{\circ} \mathrm{C}$, ignition did not occur despite significant amounts of chemical reaction. (ND3, DA1) Nelson saw no 
explosions in untriggered experiments at the $10 \mathrm{~g}$ level, and Page et al. found it necessary to use a trigger explosion to initiate steam explosions in 1-kg masses of Al-Li alloy. (PC1)

Any hydrogen generated by chemical reaction may also contribute to the net explosive energy through its own oxidation. Hydrogen generated by a steam explosion with chemical reaction is likely to deflagrate as soon as it encounters air; it may be hot, and there will be plenty of hot metal fragments present to cause ignition.

Chemical reaction has also been observed in vapor explosions involving other materials. FITS tests quantified the generation of hydrogen in ironwater steam explosions. (BM1) Hydrogen was also observed in iron oxidewater systems. (ND1)

\section{F. Explosion Efficiency}

The efficiency of steam explosions is of great interest and has sometimes been the stuff of controversy. The efficiency is here defined as the conversion of heat energy to mechanical work, further broken down as follows:

$\mathrm{Ef}=(\mathrm{Wk}+\mathrm{Wp}) /\left(\mathrm{Qm}^{\circ}-\mathrm{Qmf}\right)$

Where Ef is efficiency, Wk is the kinetic energy of exploding material, Wp is the work done in compressing gas, $\mathrm{Qm}^{\circ}$ is the heat content of the melt, and $\mathrm{Qmf}$ is the final heat content of the formerly molten material once it has cooled to ambient conditions. It is apparent that in an open system Wp must go to zero as no overpressure will remain at the end of the event. The expanding gas therefore does work only to the extent that it is able to create kinetic energy in other materials. This will be higher in a tamped system like a gun barrel or the pipe used by Rightley and Beck in one of their experiments. (RB1)

Calculated efficiencies using idealized conditions can range to $40 \%$ or more. (MC1) Real efficiencies are usually of the order of a few per cent or less. (FA5,AH2,NF1) Some of the differences can be accounted for straightforwardly in thermodynamic terms: by including the response of fluids surrounding the exploding mixture, Hall has shown that efficiencies of a few per cent are obtained, in good agreement with Winfrith experiments. (AH2) If some of the melt is not involved effectively in the explosion, the efficiency would be even less. Of course, in experiments in which chemical energy is added to the system, the apparent efficiency calculated by this equation without explicity considering the chemical energy can be very high, even exceeding $100 \%$. (RB1)

Efficiencies are further considered in the illustrative calculations section below. 


\section{G. Scale Effects}

The effect of increasing mass on the probability and consequences of a steam explosion is a matter of great interest. For reactor accidents in which much of the core melts and relocates, there is a possibility of steam explosions involving many $\mathrm{kg}$ of material. Such explosions could do great damage, either through blast or by generating missiles. Evaluation of the likelihood of such explosions and their consequences involves considerations both of probability and of the scaling of the blast with melt mass.

There is clearly a scale effect on the probability of triggering a steam explosion. For molten aluminum falling through water, Nelson has shown that with tens of grams of aluminum, natural triggering rarely or never occurs. On the 1-kg level, even with lithium present, the available data indicate that spontaneous triggering of a steam explosion is still a rare event. The aluminum industry experiments have shown that spontaneous triggering is more likely for tens of kilograms of melt falling into a confined volume. One of the Sandia tests of about $7 \mathrm{~kg}$ apparently self-triggered. Greene's experimental data previously cited suggest that self-triggering at these scales is less likely in a less confined volume. Above the level of $25 \mathrm{~kg}$ of melt, the data base is sparse, and consists largely of diagnostic studies of industrial accidents. Nonetheless, from the work in the aluminum industry, it is clear that for such large masses there is a substantial probability of spontaneous triggering.

The effect of melt mass on explosive energy is less we!l defined. The accepted steam explosion model assumes good mixing of melt and water, and this is less and less likely as the melt mass increases. This effect might decrease the explosive yield per $\mathrm{kg}$ of melt. On the other hand, Berman and Beck (BB1) have modeled steam explosions by analogy with chemical explosions, and predicted that maximum propagation rates and energy releases require large mixed volumes on the scale of meters in size. This is likely to remain a speculative premise, as the experiments that might confirm or refute it would be very difficult and expensive. In addition, few real systems would reach this magnitude.

\section{Modeling and Calculation}

\section{A. Steam Explosion Models.}

Numerical modeling of steam explosions has been attempted in order to gain insights into the processes occurring in the explosions, and to predict explosion efficiencies. Such models can be extremely complex. A rigorous model would have to keep track of heat transfer, phase changes, and momenta for a system consisting of at least three different phases which are being blown apart at different rates. (The velocity of a shock wave in the liquid phases is much higher than its velocity in steam.) Despite these 
demanding requirements, several numerical models of steam explosion phenomena have been attempted. The status of these efforts is contained in a recent review by Fletcher and Anderson. (FA1). These authors emphasize the difficulties in this process, noting in their summary that:

"We note that many of the physical features of a vapour explosion are not well understood and conclude that the current generation of mathematical models do not address many of the complexities of a real explosion."

In the body of the review the authors identify some of these complexities: the first is that the premixing process as described in the first part of this document generally is absent or at most incomplete in real explosions; the second is that little consideration has been given to modeling explosions in the stratified mode; another is that temperature gradients exist throughout the system and are very hard to quantify. All these points are cogent, and make quantitative modeling of a steam explosion very difficult. Still, it is useful to undertake numerical modeling of explosions to gain understanding of how various factors affect the steam explosion process. Several recent efforts are described in the following section.

An alternative sort of modeling was proposed by Berman and Beck (BB1) who treat steam explosions in terms of chemical explosion theory and found numerous analogies. They have suggested alternative modeling methods which appear to be unexplored, so far.

\section{B. Computer Models.}

Several computer models have been developed; this discussion covers the most recent. In general these models assume that a sufficient trigger occurs after melt has entered water; the triggering process itself is not modeled. Additionally, they are in general models for distributions of melt in water rather than for stratified systems.

Corradini and his co-workers have developed a steam explosion model which has been used to analyze steam explosions in SRS reactors. It is an extension of a previously published model. (OC1) A description of the model and its operation is here excerpted from its code manual. (CB1)

"This is a computer simulation model for predicting the behavior of a large scale vapor explosion within the open system. The system consists of five different constituents: (1) initially molten fuel, (2) fragmented fuel with a final debris size, (3) vapor coolant interacting with a coolant liquid, (4) (missing in the manual), (5) a coolant slug above the explosion zone.

"The code -- starts by using an assumed value of the global fragmentation time --. This time determines the fuel fragmentation size based on complete fragment quenching and the transient heat conduction theory --. 
"Then the code calculates the thermal properties and the initial surface temperature of the fuel. Again the code calls the subroutine -- to get the specific volume of vapor coolant. The initial mass, energy, and volume of each component is calculated and the initial void fraction, the initial position of slug, and the initial thermal penetration depth of the liquid coolant are calculated. The total mass and the energy to be conserved during the calculation are calculated at the same time."

Provision is made for testing and adjusting of parameters based on hand calculations or experimental data. The Corradini code has been compared to data from the Sandia EXO-FITS experimental series. Qualitative agreement with trends was observed.

Theofanous and his co-workers have developed a model for predicting the effects of a steam explosion within a LWR reactor vessel. Their model treats premixing using the K-FIX computer cole. Two-fluid calculations are done to obtain qualitative results for a corium-water system. (AT1) Calculations of the resulting explosions were done parametrically assuming various explosion volumes and magnitudes, and thermodynamically ideal energy conversion. (AT2) It is recognized that the latter may give high values, but the purpose of the study was to calculate conservative values of the stress imposed on a reactor vessel by an internal explosion. This treatment has proven unusually controversial, and gave rise to a heated correspondence regarding its validity. (MB1,MC2,BM2,TT1)

The IFCI computer code, developed at Sandia National Laboratory, (MY1) is similar to the Corradini model in attempting to account for heat and momentum in the several phases. It is based on the MELPROG code, which is designed to calculate the events occurring during core melting in a LWR. MELPROG contains a phase change model, a heat transfer and boiling model, a water equation of state, and elaborate flow models. IFCI has added to this extensions that include fuel fragmentation, ard a convection model for melt surface area. It also extends the equation of state into the supercritical region, and describes the interactions of molten fuel with the other constituents of the system. The author found that this model gave a good comparison with mixing phenomena occurring in nonexplosive FITS tests at Sandia. However, the boiling model obtained from MELPROG did not correspond well to the observed FCI phenomena. The published version of IFCI appears, therefore, to be incomplete for describing FCI phenomena in detail.

Abdel-Khalik and his co-workers have extended the K-FIX code to three dimensions to model the course of steam explosions. (FA2,FA3) In their treatment the processes occurring at the beginning of an explosion are not modeled, but the initial explosion parameters are specified, and the subsequent course of the explosion is then calculated. The results can be used with structural response codes to predict the effects of an explosion on 
surrounding buildings and equipment. A sample calculation has been made to predict the course of an explosion on the floor of a SRS reactor. (FA4)

\section{Mlustrative Calculations}

\section{a. Introduction}

In this section a number of scoping calculations on individual aspects of heat transfer, chemical reaction, etc., are made and compared to values obtained from experiments in the literature. The purpose of these calculations is to gain a quantitative understanding of phenomena occurring in a steam explosion. The results are used in the following section to interpret some of the recent experiments performed under the Severe Accident Analysis Program. The assumption is again made that SRP fuels, which contain a few mole \% uranium, can be approximated by pure aluminum.

\section{b. Data and Experimental Results}

The following physical constants are used in the calculations in this section:

Specific heat of water: $1.0 \mathrm{cal} / \mathrm{g}{ }^{\circ} \mathrm{K}(\mathrm{HC1})$

Density of water: $1.0 \mathrm{~kg} / \mathrm{liter}(\mathrm{HC} 1)$

Specific heat of aluminum: $0.215 \mathrm{cal} / \mathrm{g}{ }^{\circ} \mathrm{K}$ (MH3)

Density of aluminum: $2.70 \mathrm{~kg} /$ liter (HC1)

Heat of fusion of aluminum: $94.5 \mathrm{cal} / \mathrm{g}$ ( $\mathrm{MH} 3$ )

Heat of vaporization of water: $540 \mathrm{cal} / \mathrm{g}$ (HC1)

Heat of reaction $\left(\Delta \mathrm{F}^{\circ}\right)$ of water with aluminum: $103.35 \mathrm{kcal} / \mathrm{mole} \mathrm{Al}$ or 3.83 $\mathrm{kcal} / \mathrm{g} \mathrm{Al}$ at $25^{\circ} \mathrm{C}, 104.9 \mathrm{kcal} / \mathrm{mole} \mathrm{Al}$ or $3.89 \mathrm{kcal} / \mathrm{g} \mathrm{Al}$ at $100^{\circ} \mathrm{C}$. (WL1)

Thermal conductivity of water, $100^{\circ} \mathrm{C}: 0.0016 \mathrm{cal} / \mathrm{cm} \mathrm{sec}{ }^{\circ} \mathrm{K}(\mathrm{BS} 2)$

Thermal conductivity of aluminum, $700^{\circ} \mathrm{C}: 0.247 \mathrm{cal} / \mathrm{cm} \mathrm{sec}{ }^{\circ} \mathrm{K}$ (BS2)

\section{c. Calculations of Heat Transfer}

The following calculations assume that a steam explosion is the result of direct thermal contact between melt and water. This premise is not universally accepted; for example, the Corradini model presumes that heat transfer can occur through rapid heating of steam by dispersed particles. However, as the direct contact premise lends itself to calculation and gives interesting correlations with experimental data, it is adopted here. The purpose of the calcuation is to compare the implications of heat transfer calculations for particle size with size distributions actually observed. They are found to be consistent.

The time scale for heat transfer from melt to water can be estimated from experimental observation. Makino and Michiyoshi conducted experiments on the nucleation of steam bubbles following contact between water and a heated surface. (MM1) Their results, extrapolated, would indicate that 
steam formation will occur within $10^{-4}$ sec or less following contact. Steam formation would therefore occur within this short time and would separate melt and liquid water. This is consistent with high speed motion pictures such as those made by Nelson, which show that the initiation of steam explosions appears to occur in much less than a millisecond. (LN1)

Observation of explosions shows a similar time scrle. Water and fragments typically are blown apart at rates of hundreds of meters per second. As the initial scale of the system is typically of the order of tens of $\mathrm{cm}$, the maximum time of contact for effective heat transfer is less than a millisecond. This requires intimate mixing on a very small scale, as shown by the following calculation.

Note first that if it is assumed that the aluminum and water phases are in good thermal contact, heat transfer is limited by the heat flow through the water phase. As the data in the previous section show, the heat transfer by conduction through liquid aluminum is more than two orders of magnitude faster than through water. Thus to a first approximation the aluminum can be assumed to be at a uniform temperature throughout, and water offers the principal resistance to heat flow.

The heat available to the water during the period of intimate contact can be calculated on the basis of the contact time. Equilibrium is not reached, but the thermal conductivity equation can be used to estimate heat flows (and therefore superheating) as a function of distance from the liquid metal surface.

The equation for heat flow from a hot surface across a given thickness (y) of a medium to a colder area is given by the following equation:

$\mathrm{Q}=\mathrm{KAt} \Delta \mathrm{T} / \mathrm{y}$

Where $\mathrm{Q}$ is heat in calories, $\mathrm{K}$ is the thermal conductivity of the medium, $\mathrm{A}$ is the area of the surface, $t$ is time in seconds, $\Delta T$ is the temperature differential across the medium in Kelvin degrees, and $\mathbf{y}$ is the thickness.

This calculation is applied to calculate the heat flowing through water in contact with a flat surface of melt on unit area at various distances from the melt surface. It is assumed that the two liquids remain in contact for 0.1 milliseconds before being separated by steam formation. In the above equation, $\mathrm{K}=0.0016 \mathrm{cal} / \mathrm{cm} \mathrm{sec}{ }^{\circ} \mathrm{K}, \mathrm{t}=10^{-4} \mathrm{sec}, \mathrm{A}$ is taken to be $1 \mathrm{~cm}^{2}$, and $\Delta \mathrm{T}$ is typically $600^{\circ} \mathrm{K}$ (corresponding to $700^{\circ} \mathrm{C}$ at the metal-water interface). The results are shown in the following table. (Note that this is an approximate calculation, which does not take into account the rapid change of temperature through the water layer. More rigorous calculations are planned. However, it was felt that these simple calculations would help the reader understand the constraints placed on the system by heat transfer limitations.) 


$\begin{array}{lcc}\text { Water thickness, cm } & \text { Heat flow, cal } & \text { Heat, cal } / \mathrm{cm}^{3} \\ & & \\ 0.0001 & 0.96 & 9600 \\ 0.0003 & 0.32 & 1070 \\ 0.0005 & 0.192 & 384 \\ 0.001 & 0.096 & 96 \\ 0.01 & 0.0096 & 0.96 \\ 0.1 & 0.00096 & 0.0096\end{array}$

From these values, and the specific heat and density of water, it can be seen that the water within a few micrometers of the metal surface comes to near thermal equilibrium with the metal during this time, and is strongly superheated. (Any effects that superheating may have on the flow of heat are, of course, neglected in thi $\approx$ illustrative calculation.) It is interesting to compare these calculations $w_{2}$ h the observed heat transfer rates of $10^{7}$ $\mathrm{W} / \mathrm{m}^{2}$ measured by Makino and Michiyoshi at a $\Delta \mathrm{T}$ of $260^{\circ} \mathrm{K}$. (MM1) The heat flow at $0.001 \mathrm{~cm}$ calculated above is about $4 \times 10^{7} \mathrm{~W} / \mathrm{m}^{2}$. This comparison suggests that the sort of calculation done here is reasonable.

The heat flow just calculated is sufficient to vaporize all the water in contact with the metal surface to a distance of around 5 micrometers. This is a fairly trivial amount of steam production for massive metal, because the contact surface is limited, but steam production is much greater should the metal be broken up into very small drops that are intimately mixed with water. For drops smaller than a millimeter in size, the heat flow into a layer $0.0005 \mathrm{~cm}$ thick can be a substantial part of the heat content of the drop, as indicated in the following table. Once again a metal temperature (and contact temperature) of $700^{\circ} \mathrm{C}$ and a contact time of 0.0001 seconds are assumed. (The table is calculated on the basis of a constant melt temperature, and the decrease of heat flow with decreasing melt temperature is ignored. The actual contact temperature will be somewhat below the melt temperature. These factors could be corrected in a rigorous calculation, but for illustration the approximations made are close enough.)

$\begin{array}{lll}\begin{array}{c}\text { Drop Diameter } \\ \text { cm }\end{array} & \begin{array}{c}\text { Heat Content } \\ \text { cal }\end{array} & \begin{array}{c}\text { Heat Flow to Water, cal } \\ (0.0005 \mathrm{~cm} \text { water thickness })\end{array} \\ 0.002 & 2.53 \times 10-6 & 2.41 \times 10-6 \\ 0.02 & 2.53 \times 10-3 & 2.41 \times 10-4 \\ 0.06 & 6.83 \times 10-2 & 2.17 \times 10-3 \\ 0.2 & 2.53 & 2.41 \times 10-2\end{array}$

This table shows that most heat is lost from drops 20 micrometers in radius, as might be expected; but for drops $0.6 \mathrm{~mm}$ in diameter, only around $3 \%$ of the heat is transferred to the water during the contact time considered. These calculations help define conditions necessary for a damaging steam explosion: contact between the metal and the water must 
be on the scale of $0.02 \mathrm{~cm}$, or smaller, for a major fraction of the heat to be converted efficiently into steam, and thus into mechanical energy.

These results can be compared with the results obtained by Nelson on the particles sizes of aluminum fragments from steam explosions. (Figure 6) (NF1) The mass median size was slightly over $0.04 \mathrm{~cm}$; more than $90 \%$ was larger than $0.01 \mathrm{~cm}$, and only a few per cent exceeded $0.1 \mathrm{~cm}$. The breakup into droplets of sub-mm size, which the above calculations suggest is required for a steam explosion to occur, clearly is occurring in the course of the initial contact between melt and water. The implications of this will be discussed later.

\section{d. Steam Explosion Efficiencies and Their Implications}

As discussed previously, although ideal calculations have suggested that as much as $40 \%$ of the heat energy of the melt undergoing a steam explosion might be converted to work, investigators have found that steam explosions are generally much less than $10 \%$ efficient. This value, in connection with other information, tells something about steam explosion mechanisms, and about the expansion phase of the explosion.

Consider, for example, the system described in Reference (AL1). Appro:cimately $20 \mathrm{~kg}$ of metal at $800^{\circ} \mathrm{C}$ is dropped into $55 \mathrm{~kg}$ of water at ambient temperature. The available thermal energy for vaporizing water is the heat given off by the aluminum in cooling from $800^{\circ}$ to $100^{\circ}$, which is $2.05 \times 10^{7}$ Joules. If the explosion is $20 \%$ efficient, the kinetic energy of the system is $4.10 \times 10^{6}$ Joules. Assuming that the whole system is accelerated, the average velocity of the components can be calculated from

$\mathrm{V}=(2 \mathrm{E} / \mathrm{M})^{0.5}=\left(8.20 \times 10^{6} / 75\right)^{0.5}=331 \mathrm{~m} / \mathrm{sec}$.

For an explosion that is $10 \%$ efficient, the corresponding velocity is about $234 \mathrm{~m} / \mathrm{sec}$. Velocities of this magnitude are in fact observed in steam explcsions, although they may involve only a portion of the water-steam mixture. Note that the aluminum industry experiments are likely to show relatively high efficiencies, because they are done in a steel box which can have a tamping effect.

\section{e. Chemical Reaction of Aluminum and Water}

As previously indicated, there is experimental evidence of rapid reaction (burning) of $\mathrm{Al}$ by water on a time scale of $10^{-4}$ to $10^{-3}$ seconds. This is partially substantiated by recovery of aluminum oxide following the experiment, although some or most of this may be the result of oxidation of hot aluminum particles by air during the explosion. There is, in fact, good evidence that only aluminum-air burning occurred in some explosions where the characteristic bright light of a violent explosion was observed. (AB1) However, Nelsor's experiment, in which aluminum ignition occurred in an artificially triggered small drop explosion, makes it clear 
that aluminum-water chemical reaction can occur during a steam explosion. (ND2) The reaction adds to the violence of the explosion by generating both heat and hydrogen gas. Nelson's experiment is the only well-controlled experiment in which ignition was observed during a steam explosion, and his results are important for interpretation.

An estimate of the energy released by burning can be made from the previously cited studies (LM1) in which aluminum particles $0.36 \mathrm{~mm}$ in diameter burned to completion underwater in $213 \mathrm{msec}$. If it is assumed that burning is linear, $i$. e. that the reaction proceeds inward at a constant rate, then this rate is about $8.5 \times 10^{-4} \mathrm{~mm} / \mathrm{msec}$. From this the fraction of aluminum reacted may be calculated for various small drop sizes as follows:

\begin{tabular}{lllrr}
$\begin{array}{l}\text { Drop Diameter } \\
\mathrm{cm}\end{array}$ & $\begin{array}{l}\text { VReacted } \\
0.1 \mathrm{msec}\end{array}$ & $\begin{array}{c}\text { VReacted } \\
1 \mathrm{msec}\end{array}$ & $\begin{array}{c}\text { Fraction } \\
\text { Reacted }\end{array}$ & \multicolumn{1}{c}{$\begin{array}{c}\text { Fraction } \\
\text { Reacted }\end{array}$} \\
& & cubic cm & \multicolumn{1}{c}{ cubic cm } & $\begin{array}{c}0.1 \mathrm{msec} \\
1 \mathrm{msec}\end{array}$ \\
0.04 & $4.27 \mathrm{E}-08$ & $4.27 \mathrm{E}-07$ & 0.001275 & 0.01275 \\
0.02 & $1.07 \mathrm{E}-08$ & $1.07 \mathrm{E}-07$ & 0.00255 & 0.0255 \\
0.01 & $2.67 \mathrm{E}-09$ & $2.67 \mathrm{E}-08$ & 0.0051 & 0.051 \\
0.005 & $6.68 \mathrm{E}-10$ & $6.68 \mathrm{E}-09$ & 0.0102 & 0.102
\end{tabular}

Nelson's data (ND2) showed that $.04 \mathrm{~cm}$ was a typical drop size in a steam explosion, but they suggested that in an explosion with chemical reaction the small drops may have been burned preferentially. (Figure 6) This is in accordance with the above calculation. The fraction of these drops that will burn is much higher. (In actuality, the burning rate is probably not linear, so this sort of calculation should only be regarded as illustrative of the trend.)

The energy produced by burning may be compared with the energy content of the aluminum. This is defined as the heat required to raise the aluminum from $100^{\circ} \mathrm{C}$ to the temperature of the melt, and includes the heat of fusion. It is the heat available to boil water. At $1100^{\circ} \mathrm{C}$ the heat content of the melt, as calculated from the data previously given, is approximately 1312 Joules per gram of aluminum. The heat of reaction of the aluminum at this temperature is about 596,000 Joules per mole, on the basis of the values in Latimer's book. (WL1) The following table compares the heat available from the two sources:

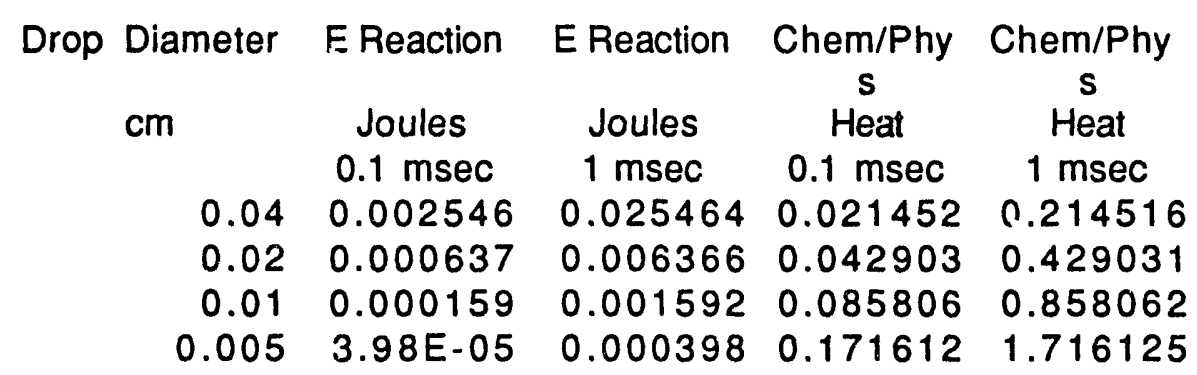


These values indicate that for the typical droplet of aluminum, $0.04 \mathrm{~cm}$ in diameter, the heat available from aluminum burning will be only a fraction of the total available heat for making steam, but for the smaller range of droplets the heat of reaction becomes very important. Also, these values probably underestimate the initial rate of aluminum reaction, which may be very fast when there is newly formed aluminum surface.

This calculation can be compared with the results obtained by Nelson in his experiment in which a steam explosion ignited a $10 \mathrm{~g} \mathrm{Al}$ droplet at $1500^{\circ} \mathrm{C}$. An expanding bubble with a volume of at least 14 liters was produced, and the associated shock wave broke the viewing window of the apparatus. It can be calculated that the heat required to produce this much steam exceeds the heat content of the molten droplet by about a factor of two. Consequently the chemical reaction energy was at least as large as the available heat energy. This requires reaction of at least $7 \%$ of the aluminum drop with water. The actual reaction was probably greater, but the reaction is bounded by the observation that at least $2 / 3$, and probably $4 / 5$, of the original aluminum was recovered unreacted. The time required for the bubble to expand to the maximum observed size was about $5 \mathrm{msec}$. However, the luminosity, indicating chemical reaction, had significantly decreased after the first msec following ignition. Presumably most of the reaction occurred within a millisecond or so.

Hydrogen production during reaction would add to the volume of expanding gas. However, this is a minor effect. Calculations show that the volume of hydrogen produced from aluminum burning underwater is about oneeighth the volume of the steam produced from the heat released to the surrounding water.

It is interesting to note that in the SPERT-I and SL-1 reactor incidents it was estimated that the chemical reaction in the steam explosion involved of the order of 5 to 10 per cent of the molten material. (SZ1) This suggests that Nelson's results may be scalable to a much larger size range. This would be a very useful conclusion in setting an upper limit to the involvement of chemical energy in the steam explosion.

\section{Conclusions and Recommendations}

\section{Conclusions:}

The interaction of molten aluminum (or aluminum-based reactor fuel) with water can lead to a steam explosion if a triggering shock occurs to bring the two fluids into intimate contact. Ordinary shocks produced by boiling processes are about an order of magnitude too low to cause an explosion, but reflections off surfaces and corners can increase the local shock pressure, and may be responsible for many of the experimentally observed "spontaneous" triggering incidents. The magnitude of the triggering shock may be directly related to the magnitude of the explosion, because a shock that is effective over a large volume can bring many water- 
melt surfaces into contact in a time that is short compared to the time of the explosion. The efficiency of the resulting explosion in doing work on its surroundings will depend on their geometry.

Chemical reaction can occur when the melt is significantly superheated, and the resulting chemical energy can augment the heat energy of the melt. Experimental data suggest that chemical reaction may involve 5-10\% of the fuel; it is limited by the rate of reaction of aluminum with steam. This generates a significant amount of heat, however, which may exceed the heat energy of the melt. Metal-water reactions also generate hydrogen, which can be a safety concern under some conditions.

Many useful data regarding steam explosions have been obtained from small-scale, relatively well instrumented experiments. The illustrative calculations given above suggest that these can provide the basic data that help explain larger steam explosions.

Prototypic steam explosion studies have been possible in some cases of concern, as in the control rod melting studies conducted in support of SRS $\mathrm{K}$-Reactor restart. Well-instrumented prototypic studies can be valuable in evaluating tine likelihood of a steam explosion.

Recommendations:

There are two types of prototypic experiments that would be useful for estimating the likelihood of steam explosions in SRS reactor incidents. One would involve melt-water reactions in fuel end fittings. A few $\mathrm{kg}$ of melt could be allowed to contact water in end fitting geometry. If steam explosions occurred they could be measuied; if not, pressure pulses could be observed by transducers to see whether boiling in this geometry is likely to produce strong pressure pulses. A second would involve a pour of very hot aluminum melt into a shallow tank of water broad enough to avoid melt-water interactions at the walls. This would simulate flow to the -40 foot level in SRS reactors. Again, the local conditions could be carefully monitored. Both these experiments have the potential to be very energetic, and would have to be done remotely in a safe location.

The other experiment of great interest would be the comparison of steam explosions in uranium-aluminum melts with those in aluminum alone. Such experiments were intended at Sandia National Laboratory, but because of various experimental and administrative problems were never achieved. They are still very desirable in terms if establishing that all the other aluminum-water experiments are valid for predicting molten fuelwater interactions.

Existing computer models of steam explosions are probably good enough for modeling the expansion phase of the explosion. More good experimental data on triggering are needed to be able to predict the triggering phase of the explosion and the extent of involvement of the melt mass in the 
explosion. Relatively small-scale experiments would be most useful to this end.

\section{References}

AA1 R. Anderson, D. Armstrong, D. Cho, and A. Kras, "Experimental and Analytical Study of Vapor Explosions in Stratified Geometries", 1988 ASME/AIChE National Heat Transfer Conference, Houston, TX, July 24-27, 1988.

AA2 R. P. Anderson and D. R. Armstrong, "Experimental Study of SmallScale Explosions in an Aluminum-Water System", in Light Metals 1980, Curtis J. McMinn, Ed., Proceedings of a meeting of the AIME at Las Vegas, NV, Feb. 24-28, 1980.

AA3 Presentations by S. Epstein and others to the Aluminum Association Industry Safety Conference, Tampa, Florida, December, 1987.

AB1 A. J. Briggs, "Experimental Studies of Thermal Interactions at Winfrith", Paper SNI 6/1 of PNC N251 76-12 (Vol. 1), Proceedings of the Third Specialist meeting on Sodium/Fuel Interaction in Fast Reactors, Tokyo, March 22-26, 1976.

AC1 W. O. Alexander, A. T. Chamberlain, and F. M. Páge, ECSC Research Report 7205-16/801/08 (1982).

AH1 D. K. Allison and M. L. Hyder, "The Treatment of Rapid Steam Generation for the Loss of Fuel and Loss of Control Rod Cooling Accidents (U)", WSRC-RP-91-861, August, 1991.

AH2 Andrew N. Hall, "Outline of a New Thermodynamic Model of Energetic Fuel-Coolant Interactions", Nucl. Engg. \& Design 109, 407 (1988)

AL1 Alexis W. Lemmon, Jr., "Explosions of Molten Aluminum and Water", in Light Metals 1980, Curtis J. McMinn, Ed., Proceedings of a meeting of the AIME at Las Vegas, NV, Feb. 24-28, 1980, p. 817.

AT1 M. A. Abolfodl and T. G. Theofanous, "An Assessment of Steam Explosion-Induced Containment Failure Part II: Premixing Limits", Nucl. Sci. Engg. 97, 282 (1987).

AT2 W. H. Amorasooriya and T. G. Theofanous, "An Assessment of Steam Explosion-Induced Containment Failure Part III: Expansior and Energy Partition", Nucl. Sci. Engg. 97, 296 (1987).

BB1 Marshall Berman and David F. Beck, "Steam Explosion Triggering and Propagation: Hypotheses and Evidence", undocumented Sandia National Laboratory preprint, August 29, 1989. 
BG1 P. E. Blackburn and E. A. Gulbransen, "Aluminum Reactions with Water Vapor, Dry Oxygen, Moist Oxygen, and Moist Hydrogen Between 500 and 625", J. Electrochem. Soc. 107, 944 (1960).

BM1 M. Berman, B. W. Marshall, Jr., M. F. Young, and L. T. Pong, "Recent Results in FCI Research", presented to the NRC Water Reactor Safety Conference, October 27-31, 1986.

BM2 Billy W. Marshall, Jr., "Comments on 'An Assessment of SteamExplosion-Induced Containment Failure, Parts I-IV'", Nucl. Sci. Engg. 100, 165 (1988).

BN1 Marshall Berman and Lloyd S. Nelson, Eds., "Causes and Prevention of Melt-Water Interactions", Proceedings of a Conference held at Sandia National Laboratory, July 29, 1988.

BS1 L. Baker, Jr., and F. Simms, "Status of Technology of Oxidation and Hydrogen Generation", ANL/NPR-90/024 (Draft), September, 1990.

BS2 R. B. Bird, W. E. Stewart, and E. N. Lightfoot, Transport Phenomena, John Wiley \& Sons, New York, 1960.

CB1 Michael L. ('orradini, K. T. Bang, M. D. Oh, and J. Tang, A Code Manual for a Large-Scale Vapor Explosion Model: Non-Equilibrium and a Water/Steam Equation of State: Steam, University of Wisconsin, October, 1991.

CG1 D. H. Cho, J. D. Gabor, R. T. Purviance, and J. C. Cassulo, "Scoping Tests on the Potential for Lithium/Aluminum Steam Explosions in an SRS Septifoil (U)", WSRC-RP-91-0952, September, 1991.

DA1 D. K. Allison, "Summary of Rapid Steam Generation Experiments Performed at Sandia National Laboratories", WSRC-RP-91-889, October, 1991.

DA2 D. K. Allison, "Summary of Rapid Steam Generation Experiments Performed at Brookhaven National Laboratory (U), WSRC-RP-91-888, October, 1991.

DC1 D. H. Cho, Argonne National Laboratory, Private Communication, February, 1992.

EH1 P. G. Ellison, M. L. Hyder, C. L. Angerman, and J. P. Morin, "A Phenomenological Assessment of Nuclear Metallic Fuel Melt Behavior During Severe Accidents (U)", WSRC-RP-90-1130, October, 1990. 
ES1 E. G. Silver, "SPERT Program Status Report", Nucl. Safety 5, 151 (1964).

FA1 D. F. Fletcher \& R. P. Anderson, "A Review of the Pressure-Induced Propagation Models of the Vapour Explosion Process", Prog. Nucl Energy 23, 137 (1990).

FA2 Yousef M. Farawila, Said I. Abdel-Khalik, and Peter J. Halvorson, "Numerical Modelling of the Expansion Phase of Steam Explosions Part I: Method and Validation", WSRC-RP-90-1215, February, 1990.

FA3 Yousef M. Farawila, Said I. Abdel-Khalik, and Peter J. Halvorson, "K-FIX(GT): A Computer Program for Modelling the Expansion Phase of Steam Explosions within Complex Three Dimensional Cavities. User's Manual", WSRC-RP-90-1216, February, 1990.

FA4 Yousef M. Farawila, Said I. Abdel-Khalik, and Peter J. Halvorson, "Numerical Modelling of the Expansion Phase of Steam Explosions Part II: Application to the Savannah River Plant", WSRC-RP-90-1214, February, 1990.

FA5 Y. M. Farawila and S. I. Abdel-Khalik, "On the Calculation of Steam Explosion Conversion Ratios from Experimental Data", Nucl. Sci. Engg. 104, 288 (1990).

FR1 C. J. Fry and C. H. Robinson, "Results from Selected Experiments Performed in the THERMIR Facility at AEE Winfrith", AEEW-M1778, May, 1980.

FR2 Frigyes Reisch, "Technical Note: How Chernobyl Happened: a Second Opinion", Nucl. Safety 28, 43 (1987).

GG1 George A. Greene, Brookhaven National Laboratory, "Boiling Heat Transfer, Debris Coolability, and Explosive Interactions from a Scratified Configuration", presented to the USDOE review group on Deterministic Severe Accident Criteria for the HWR New Production Reactor, Albuquerque, NM, March, 1991.

GG2 George A. Greene, Brookhaven National Laboratory, report in preparation.

GL1 G. Long, "Explosions of Molten Aluminum in Water -- Causes and Prevention", Metal Progress 71, 107 (May, 1951).

HB1 P. D. Hess and K. J. Brondyke, "Study of Explosions of Molten Aluminum in Water", Metal Progress 95, 93 (April, 1969).

HC1 Handbook of Chemistry and Physics, 46th Edition, Chemical Rubber Co, Cleveland, Ohio, 1965. 
HH1 H. M. Higgins, "A Study of the Reaction of Metals and Water", Aerojet-General Corporation Report AECD-3664, April 15, 1955.

HM1 P. D. Hess, R. E. Miller, W. E. Wahnsiedler, and C. N. Cochran, Molten Aluminum/Water Explosions - 1979, The Aluminum Association, Washington, D. C., October 15, 1979.

IS1 M. Ishikawa, S. Shiozawa, T. Wakabayashi, N. Ohnishi, and H. Mochizuki, "An Examination of the Accident Scenario in the Chernobyl Nuclear Power Station", Nucl. Safety 28, 448 (1987).

JJ1 J. E. Jacobi, ALCOA, Private Communication, April 19, 1991.

LB1 Louis Baker, Jr., "Metal-Water Reactions", Nucl. Safety 7, 25, Fall, 1965.

LF1 John H. Lee and David L. Frost, "Steam Explosions, Major Problems and Current Status", in Dynamics of Explosions, p. 436, American Institute of Aeronautics and Astronautics, 1985.

LM1 L. Leibowitz and L. W. Mishler, "A Study of Aluminum-Water Reactions by Laser Heating", J. Nucl. Matl 23, 173 (1967).

MB1 Marshall Berman, "Comments on 'An Assessment of SteamExplosion-Induced Containment Failure, Parts I-IV'", Nucl. Sci. Engg. 100, 149 (1988).

MC1 M. L. Corradini, "Vapor Explosions: An Experimental Review for Accident Analysis", Nucl. Safety, in press.

MC2 M. L. Corradini, "Comments on 'An Assessment of Steam-ExplosionInduced Containment Failure, Parts I-IV'", Nucl. Sci. Engg. 100, 171 (1988).

ME1 Michael Epstein, "Underwater Vapor Phase Burning of Aluminum Particles and on Aluminum Ignition During Steam Explosions (U)", WSRC-RP-91-1001, September, 1991.

MH1 M. L. Hyder, "The Severe Accident Analysis Program for the Savannah River Nuclear Production Reactors", Nucl. Safety, in press.

MH2 J. P. Morin and M. L. Hyder, "The Reaction of Molten SRP Reactor Fuel with Water", Presented at the ANS Workshop on the Safety of Uranium-Aluminum Fueled Reactors, Idaho Falls, Idaho, March 15, 1989.

MH3 Metals Handbook, Desk Edition, American Society for Metals, Metals Park, Ohio, 1984, pp. 1-44 and 1-45. 
MM1 Kunihide Makino and Itaru Michiyoshi, "The Behavior of a Water Droplet on Heated Surfaces", Int. J. Heat Mass Transfer 27, 781 (1984).

MS1 R. W. Miller, A. H. Spano, J. Dugone, D. D. Wieland, and J. E. Houghtaling, "Experimental Results and Damage Effects of Destructive Test", Trans. Am. Nucl. Soc.6, 138 (1963).

MY1 Michael F. Young, "IFCI: An Integrated Code for Calculations of All Phases for Fuel-Coolant Interactions", NUREG/CR-5084, October, 1987.

ND1 Lloyd S. Nelson and Patricia M. Duda, "Steam Explosion Experiments with Single Drops of Iron Oxide Melted with a $\mathrm{CO}_{2}$ Laser Part II. Parametric Studies", NUREG/CR-2718, April, 1985.

ND2 Lloyd S. Nelson, Patricia M. Duda, and David A. Hyndman, "Thermal- and Ignition-Type Steam Explosions of Single Drops of Molten Aluminum", SAND91-1354, Draft, January, 1992.

ND3 Lloyd S. Nelson, Patricia M. Duda, and David A. Hyndman, "Interactions between Drops of Molten Al-Li Alloys and Liquid Water", SAND91-2191 (Draft), January, 1992.

NE1 Lloyd S. Nelson, Maureen J. Eatough, and Kenneth P. Guay, "Initiation of Explosive Molten Aluminum-Water Interactions at Wet or Underwater Surfaces", 1988 ASME/AIChE National Heat Transfer Conference, Houston, TX, July 24-27, 1988.

NF1 L. S. Nelson, T. Fuketa, M. J. Eatough, and F. J. Vigil, "The Triggering of Steam Explosions in Single Drops of Pure and Alloyed Molten Aluminum", 1990 ANS Annual Meeting, Nashville, TN, June 10-14, 1990.

NF2 L. S. Nelson, T. Fuketa, M. J. Eatough, and F. J. Vigil, "Steam Explosions of Single Drops of Molten Aluminum and 6061 Alloy", 27th National Heat Transfer Symposium of Japan, Nagoya, May 30-June 1, 1990.

OC1 M. D. Oh and M. L. Corradini, "A Propagation/Expansion Model for Large Scale Nuclear Explosions", Nuclear Science \& Engineering 95, 225 (1987).

PC1 F. M. Page, A. T. Chamberlain, and R. Grimes, "The Safety of Molten Aluminum-Lithium Alloys in the Presence of Coolants", J. de Physique C3, 48, 63 (Sept., 1987). 
RB1. M. J. Rightley and D. F. Beck, NPR/FCI EXO-FITS Experiment Series Report, NPRW-SA91-3, SAND91-1544, Sandia National Laboratories, June, 1991.

RR1 A. Robertson and A. J. Rostron, "Reaction of Molten $\mathrm{Al}$ and of Al-20 wt $\%$ U with Water Vapour", Corrosion Science 5, 425 (1965).

RT1 R. P. Taleyarkhan, "Analysis of Steam Explosions in Plate-Type, Uranium-Aluminum Fuel Test Reactors", presented at the 1989 Winter Annual ANS/SNS Conference.

SM1 A. H. Spano and R. W. Miller, "Conclusions and Implications of the SPERT-I Destructive Test", Trans. Am. Nucl. Soc. 6, 140 (1963).

SZ1 S. Zivi, "Energy Considerations in the SPERT I-D Destructive Pressure Puise", Trans. Am Nucl. Soc. 7, 501 (1964).

TT1 T. G. Theofanous, (a) "Response to 'Comments on 'An Assessment of Steam-Explosion-Induced Containment Failure, Parts I-IV', by M. Berman", Nucl. Sci. Engg. 100, 162 (1988); (b) "--by B. W. Marshall, Jr.", ibid., p. 171; (c) "--by M. L. Corradini", ibid., p. 174.

TW1 T. H. Williams, Reynolds Metals Co., Private Communication, 1991.

WB1 N. D. Woody and M. D. Brandyberry, eds., Savannah River Site Reactor Safety Assessment (U), WSRC-RP-91-041-DRAFT, February $28,1991$.

WL1 W. L. Latimer, Oxidation Potentials, Prentice-Hall, Englewood Cliffs, NJ, 1952.

WR1 G. R. Warren and T. W. Rice, "An Assessment of Reactor Safety Modelling Techniques Based on the Accident to the SL-1 Boiling Water Reactor", Nuclear Structural Engg. 2, 490 (1965). 


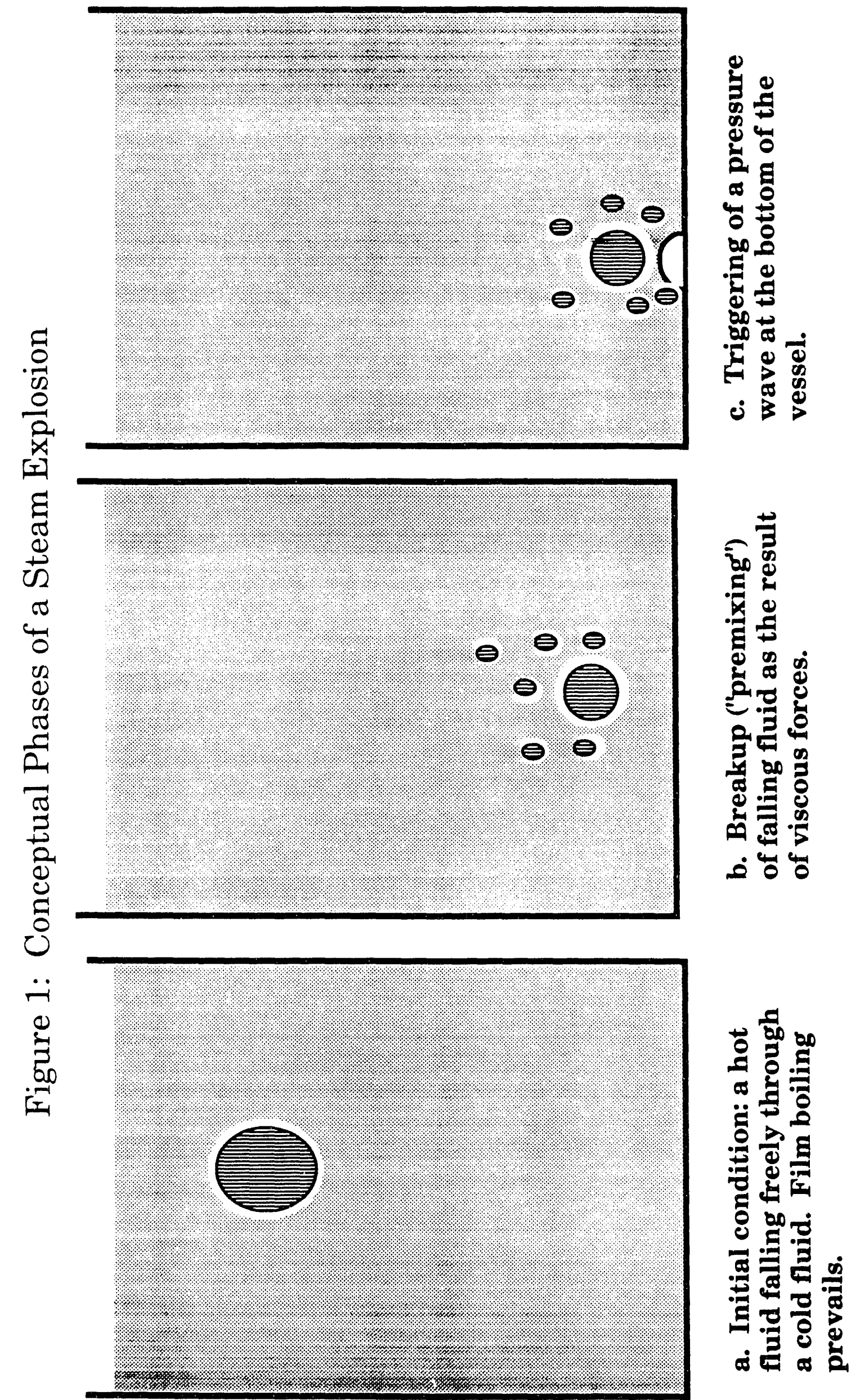




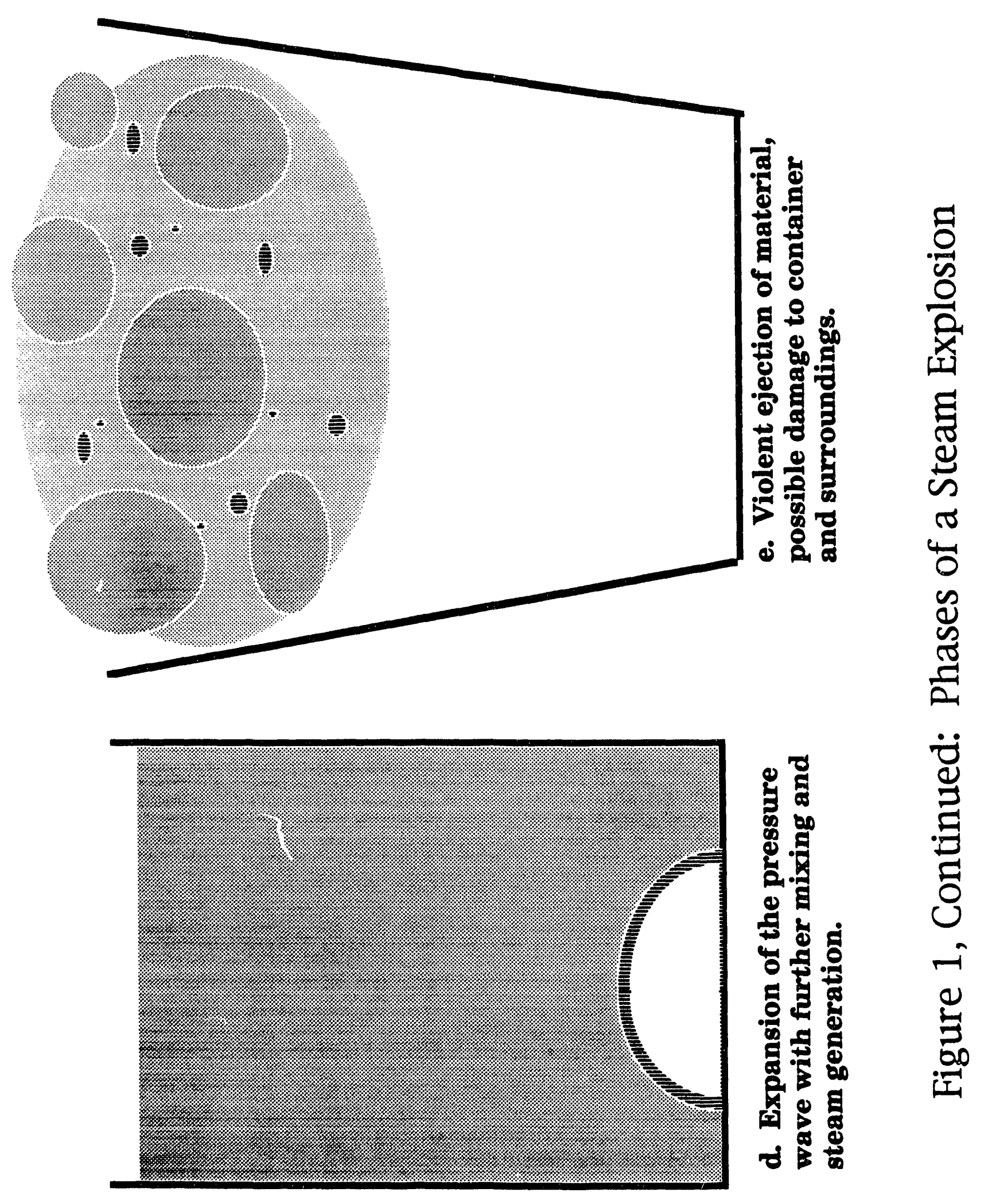




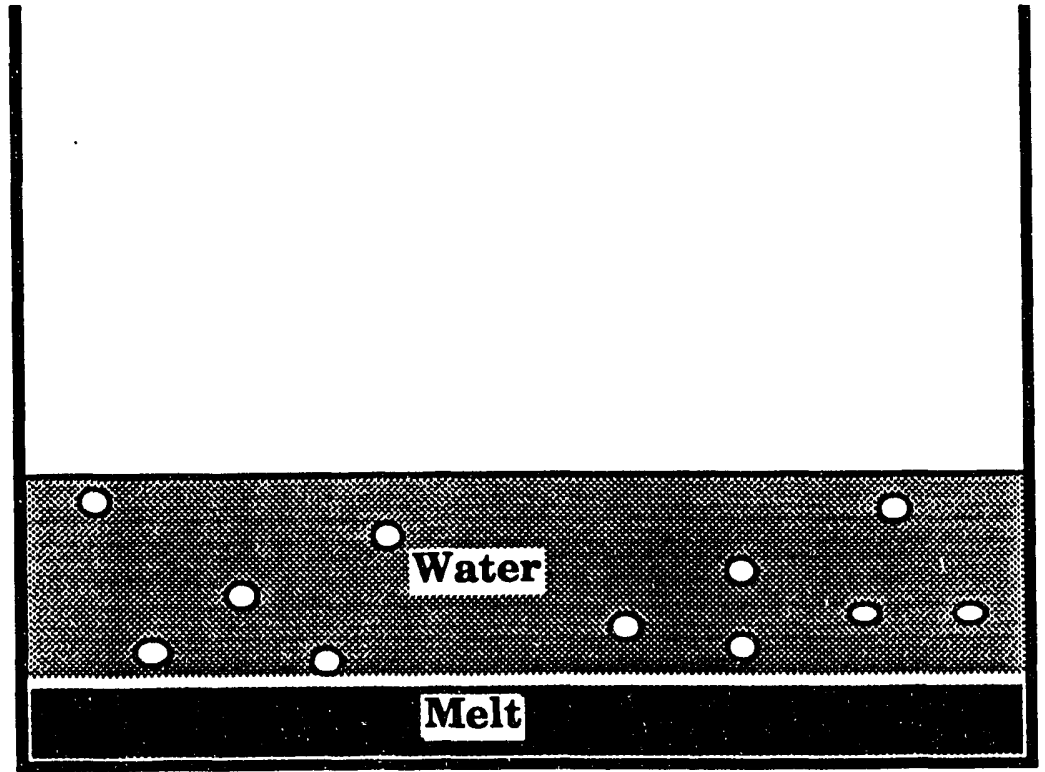

Figure 2. "Alternate Mode" or "Stratified" Contact of melt and water. Film boiling occurs at the liquid interface. A steam explosion triggered at the interface will propagate along the interface, mixing only to a limited depth in each phase. 


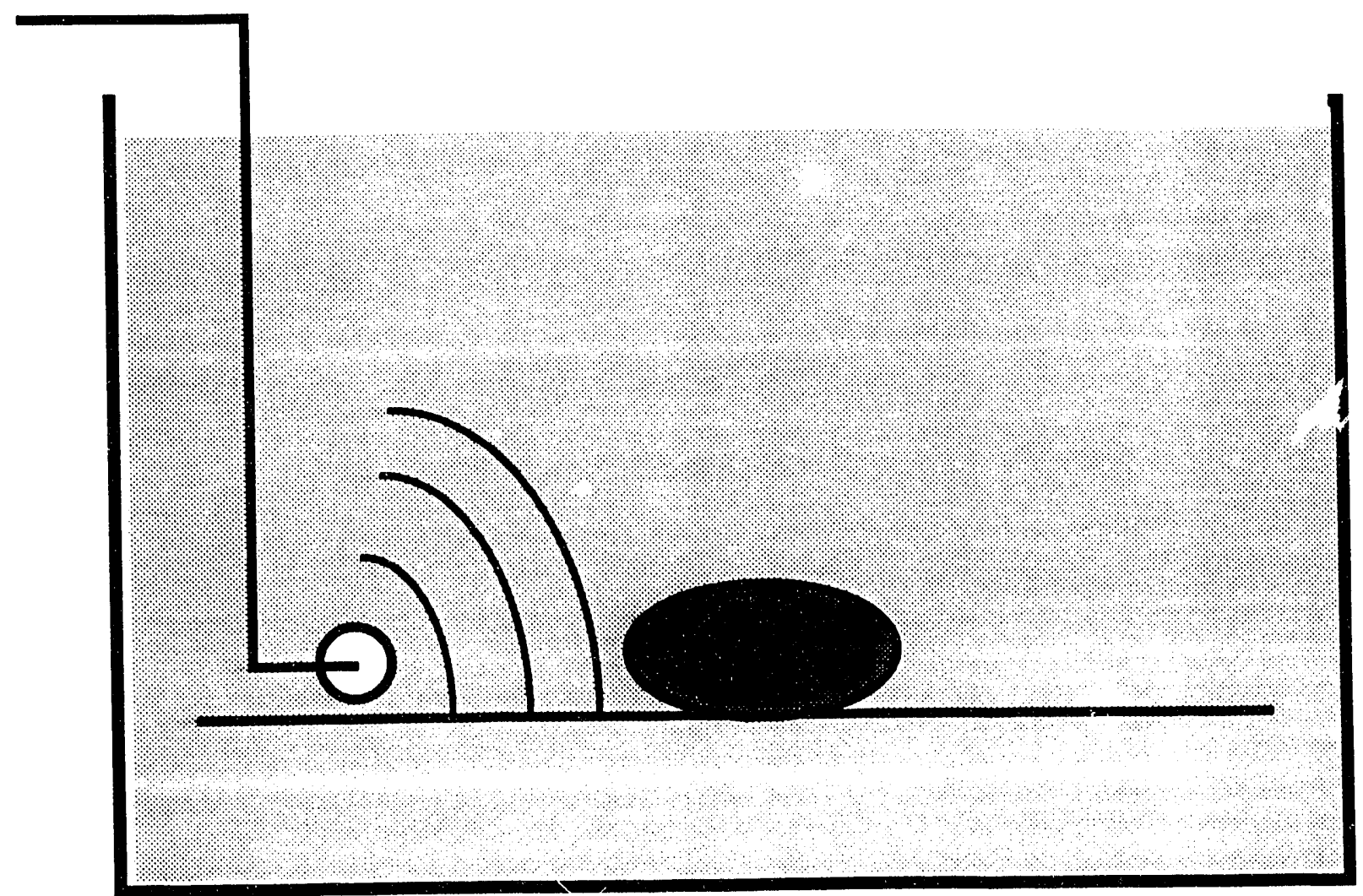

Figure 3: Nelson's experiment on surface effects on steam explosions. A molten aluminum drop is allowed to come to rest on a horizontal underwater surface before a pressure pulse is imposed by a small nearby explosion. 


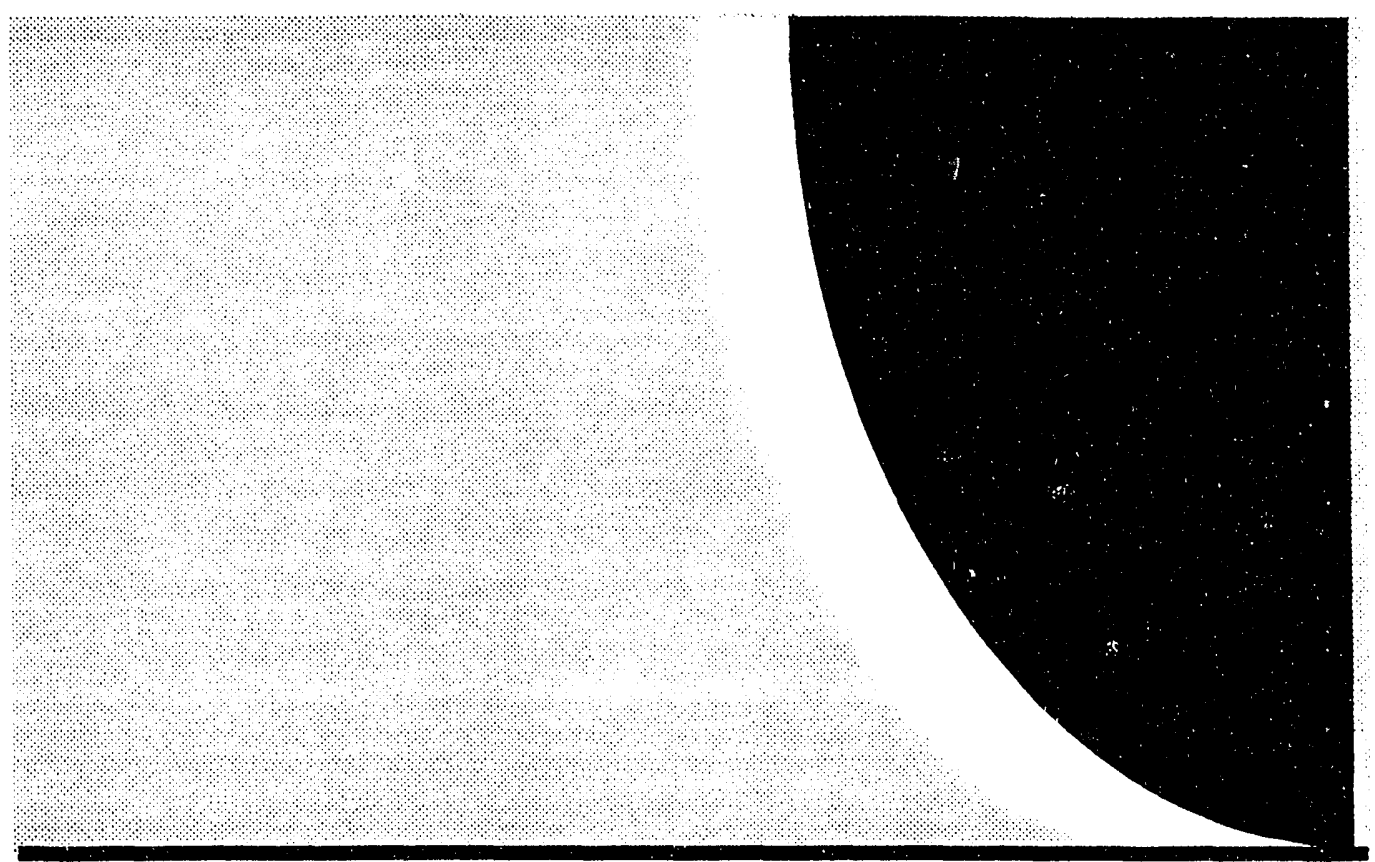

Figure 4. Melt-Water Interface on a Wetted Surface. A shock wave in the water will tend to drive the two fluids together at the interface. 


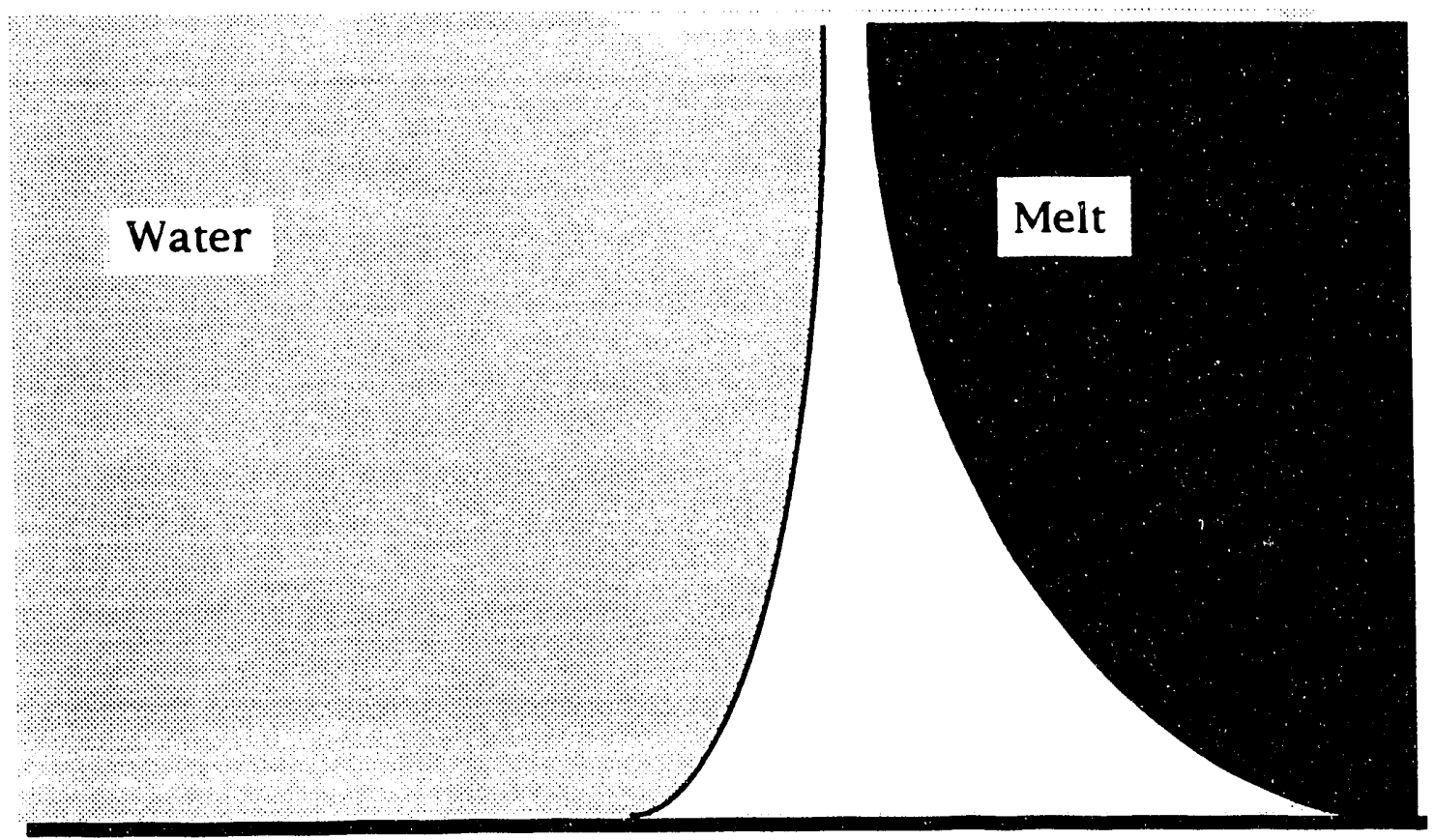

Figure 5. Hypothetical Melt-Water Interface at an Unwetted Surface. A pressure wave in the water must compress a thick layer of steam at the interface. 


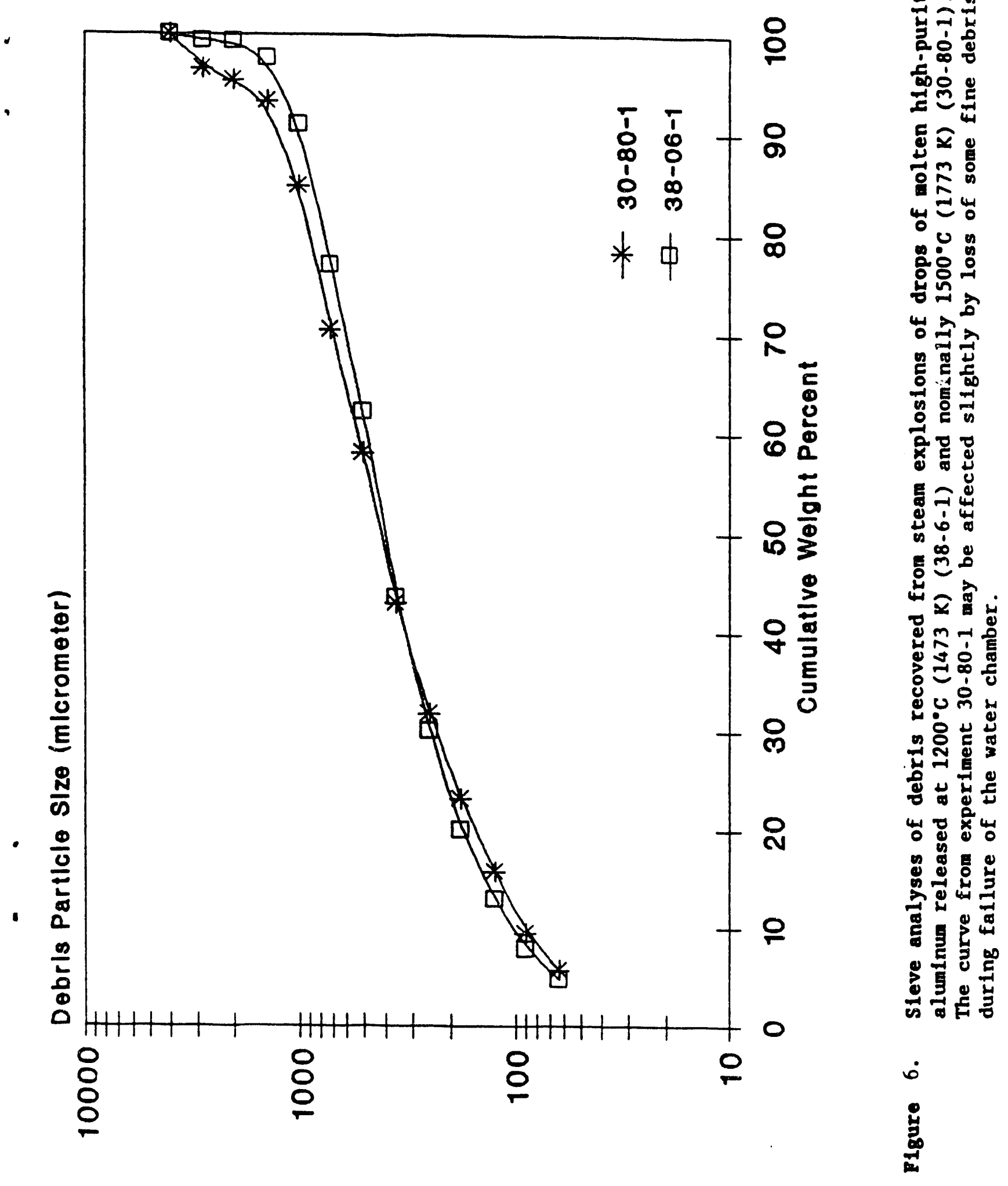



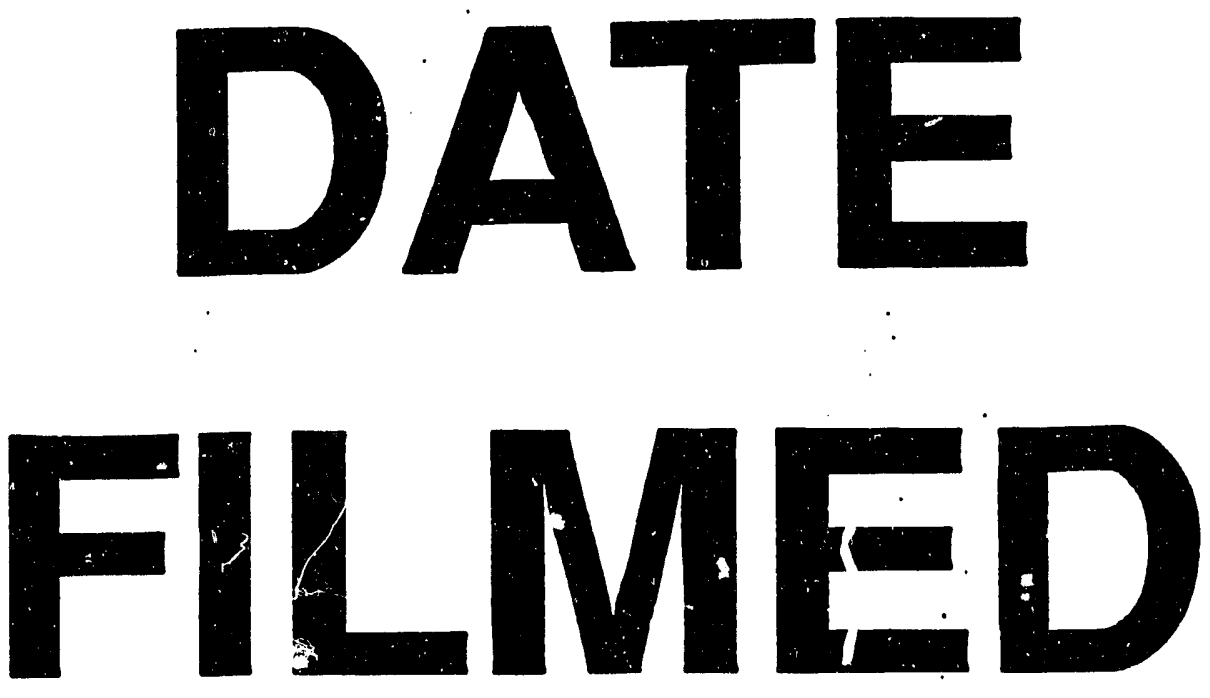

$10 / / 4 / 93$
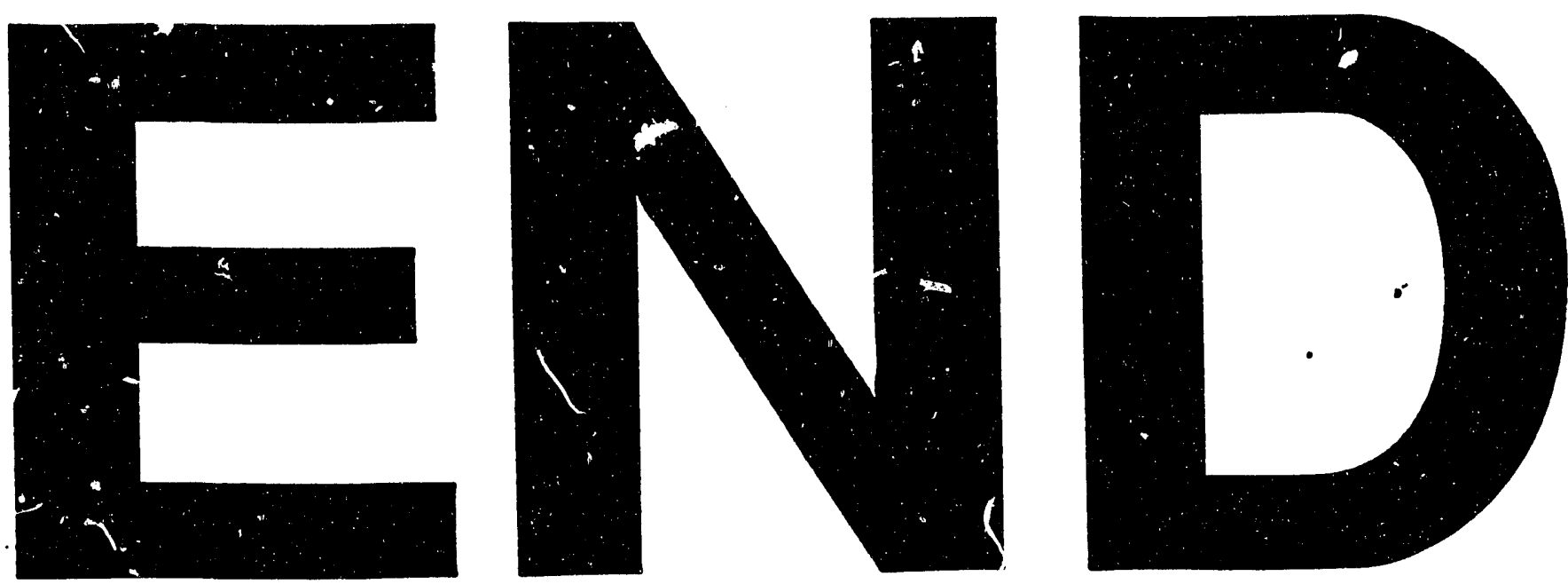
